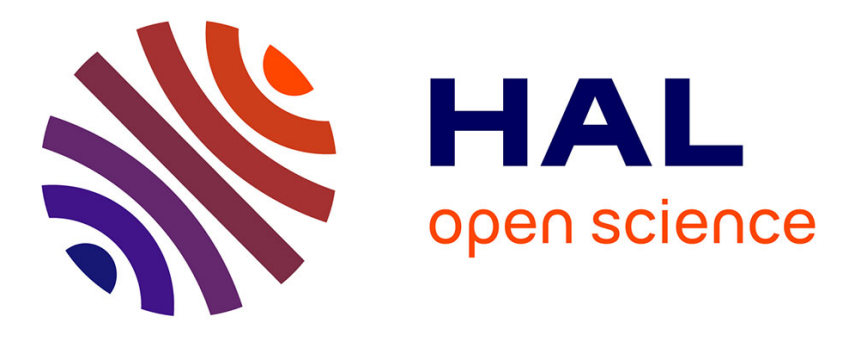

\title{
Impact of Tropical Cyclones on the Heat Budget of the South Pacific Ocean.
}

\author{
Swen Jullien, Christophe E. Menkès, Patrick Marchesiello, Nicolas C. \\ Jourdain, Matthieu Lengaigne, Ariane Koch-Larrouy, Jérôme Lefèvre, \\ Emmanuel M. Vincent, Vincent Faure
}

\section{To cite this version:}

Swen Jullien, Christophe E. Menkès, Patrick Marchesiello, Nicolas C. Jourdain, Matthieu Lengaigne, et al.. Impact of Tropical Cyclones on the Heat Budget of the South Pacific Ocean.. Journal of Physical Oceanography, 2012, 42, pp.1882-1906. 10.1175/JPO-D-11-0133.1 . hal-00766583

\section{HAL Id: hal-00766583 https://hal.science/hal-00766583}

Submitted on 10 Jun 2014

HAL is a multi-disciplinary open access archive for the deposit and dissemination of scientific research documents, whether they are published or not. The documents may come from teaching and research institutions in France or abroad, or from public or private research centers.
L'archive ouverte pluridisciplinaire HAL, est destinée au dépôt et à la diffusion de documents scientifiques de niveau recherche, publiés ou non, émanant des établissements d'enseignement et de recherche français ou étrangers, des laboratoires publics ou privés. 


\title{
Impact of Tropical Cyclones on the Heat Budget of the South Pacific Ocean
}

\author{
S. Jullien, ${ }^{*}$ C. E. Menkes,${ }^{+}$P. Marchesiello, ${ }^{*}$ N. C. Jourdain, ${ }^{\#}$ M. Lengaigne, ${ }^{@}$ \\ A. Koch-Larrouy,* J. LefÈVre, ${ }^{\&}$ E. M. Vincent,** AND V. FAURE ${ }^{++}$ \\ * Laboratoire d'Etudes en Géophysique et Océanographie Spatiale, LEGOS/OMP/CNES/CNRS/IRD/University of Toulouse, \\ Toulouse, France \\ ${ }^{+}$Institut de Recherche pour le Développement, Nouméa, New Caledonia, and Laboratoire d'Océanographie et du Climat: \\ Expérimentation et Approches Numériques, LOCEAN/UPMC/CNRS/IRD/MNHN, Paris, France \\ \# Laboratoire des Ecoulements Géophysiques et Industriels, Grenoble, France \\ @ Laboratoire d'Océanographie et du Climat: Expérimentation et Approches Numériques, LOCEAN/UPMC/CNRS/IRD/MNHN, \\ Paris, France, and National Institute of Oceanography, Goa, India \\ \& Laboratoire d'Etudes en Géophysique et Océanographie Spatiale, LEGOS/OMP/CNES/CNRS/IRD/University of Toulouse, \\ Toulouse, France, and Institut de Recherche pour le Développement, Nouméa, New Caledonia \\ ** Laboratoire d'Océanographie et du Climat: Expérimentation et Approches Numériques, LOCEAN/UPMC/CNRS/IRD/MNHN, \\ Paris, France \\ ${ }^{++}$Laboratoire d'Océanographie Physique et Biogéochimique, Marseille, France
}

(Manuscript received 20 July 2011, in final form 4 May 2012)

\begin{abstract}
The present study investigates the integrated ocean response to tropical cyclones (TCs) in the South Pacific convergence zone through a complete ocean heat budget. The TC impact analysis is based on the comparison between two long-term (1979-2003) oceanic simulations forced by a mesoscale atmospheric model solution in which extreme winds associated with cyclones are either maintained or filtered. The simulations provide a statistically robust experiment that fills a gap in the current modeling literature between coarse-resolution and short-term studies. The authors' results show a significant thermal response of the ocean to at least 500-m depth, driven by competing mixing and upwelling mechanisms. As suggested in previous studies, vertical mixing largely explains surface cooling induced by TCs. However, TC-induced upwelling of deeper waters plays an unexpected role as it partly balances the warming of subsurface waters induced by vertical mixing. Below $100 \mathrm{~m}$, vertical advection results in cooling that persists long after the storm passes and has a signature in the ocean climatology. The heat lost through TC-induced vertical advection is exported outside the cyclogenesis area with strong interannual variability. In addition, $60 \%$ of the heat input below the surface during the cyclone season is released back to the oceanic mixed layer through winter entrainment and then to the atmosphere. Therefore, seasonal modulation reduces the mean surface heat flux due to TCs to about $3 \times 10^{-3}$ PW in this region exposed to $10 \%-15 \%$ of the world's cyclones. The resulting climatological anomaly is a warming of about $0.1^{\circ} \mathrm{C}$ in the subsurface layer and cooling below the thermocline (less than $0.1^{\circ} \mathrm{C}$ ).
\end{abstract}

\section{Introduction}

Tropical cyclones (TCs) are among the most powerful extreme events of atmospheric circulation. While numerous studies have been devoted to the dynamics of TCs, comparatively few have investigated their oceanic impact. When cyclones occur, they generally induce strong oceanic surface cooling (e.g., Leipper 1967; Withee and Johnson 1976; Pudov et al. 1979; McPhaden et al. 2008), which feeds back to them, moderating their intensity

Corresponding author address: Swen Jullien, LEGOS, 14 avenue Edouard Belin, 31400 Toulouse, France.

E-mail: swen.jullien@gmail.com
(Schade and Emanuel 1999; D'Asaro et al. 2007). Understanding the surface heat balance associated with TCs is thus of major relevance to our understanding and predictive skills regarding these extreme events.

Previous studies have suggested various mechanisms affecting the ocean surface during and after a cyclone passage. From event studies using Lagrangian floats (D'Asaro et al. 2007), expendable airborne instruments (Jacob et al. 2000), or simple ocean models (Price 1981), $70 \%-85 \%$ of sea surface temperature (SST) cooling is estimated to result from extreme wind mixing of surface waters with deeper, colder ocean layers. Several case studies (e.g., Shay et al. 2000; Jaimes and Shay 2009; Shay and Uhlhorn 2008) show that vertical mixing in the 
TC wake is mainly driven by shear instability of nearinertial oscillations (NIOs) that have maximum impact 3-5 days after the TC passage. A rightward SST cooling asymmetry (in the Northern Hemisphere) is often observed (e.g., Pudov et al. 1979; McPhaden et al. 2008; Shay et al. 1992) and has been largely attributed to two phenomena. First, the wind stress asymmetry associated with TC translation speed can inject more mechanical energy into the ocean on the right side of the track (Northern Hemisphere; Shay et al. 1989; Chang and Anthes 1978). Second, mixing can be further increased because of resonance between wind and inertial currents on the same side (Price 1981; Price et al. 1994; Sanford et al. 2007; Samson et al. 2009).

Satellites provide both local and global observation of surface cooling in the cyclone wake and an estimation of the time needed to restore the surface to its prestorm conditions (Price et al. 2008). Yet, satellite observations cannot be used to acquire a complete surface heat budget that requires subsurface data. Ocean subsurface observations during cyclone occurrence indicate that subsurface oceanic background conditions may have a large control on the TC surface signature (Jacob et al. 2000; Lloyd and Vecchi 2011). The exact processes involved are difficult to assess from observations alone. Nevertheless, a few analyses conducted for specific events revealed that TC-induced upwelling may dominate the subsurface heat budget under the cyclone eye (Price et al. 1994; Huang et al. 2009) and that lateral advection may be important as a redistribution process (D'Asaro 2003; Huang et al. 2009; Price 1981; Greatbatch 1983; Vincent et al.2012). In addition to subsurface processes, it appears that latent heat fluxes from evaporation may also be of importance to the heat budget (Price 1981; Bender et al. 1993; Huang et al. 2009). However, assessing the robustness of these processes in a statistical sense and their long-term oceanic impact has remained challenging.

Quantifying subsurface warming through extreme wind mixing is another matter of debate. In the TC-induced mixing process, the heat lost near the surface is transferred down below the mixed layer. However, it is unclear to what extent other processes modulate this subsurface heat input. In particular, cooling through vertical advection may compete with mixing-induced warming (e.g., Price et al. 1994) and the heat anomaly may be redistributed away from its generation area. This raises the issue of residual effect of tropical cyclones on the regional and global ocean climate. Assuming that TC-induced surface cooling results in a permanent heat transport below the mixed layer, Emanuel (2001) estimates a relatively large heat input of $\sim 1.4 \pm 0.7 \mathrm{PW}$ below the surface. He thus suggests that TCs have an important role in the global ocean diapycnal mixing that regulates the meridional overturning circulation and, in turn, the climate system. Based on similar assumptions and dimensional analysis of vertical mixing, Sriver and Huber (2007) give a lower estimate of $0.26 \mathrm{PW}$ of heat input due to cyclones [Sriver et al. (2008) update this value to $0.35-0.60 \mathrm{PW}$ ]. More recently, Jansen et al. (2010) have argued that TC-induced heat input below the surface is overestimated since part of the heat injected in the seasonal thermocline during the summer cyclonic season is injected back through winter entrainment to the ocean surface and then to the atmosphere. Therefore, while there is general agreement that some heat is permanently injected below the mixed layer, the few attempts at quantification are very sensitive to the data used and processes accounted for in the estimation.

In the absence of a global high-resolution ocean dataset, ocean models remain the best alternative to advance our knowledge of the oceanic response to cyclones. There is still a gap between modeling case studies, which detail the oceanic response to a given or idealized event, and long-term, statistically reliable ocean climate modeling. Studies of the second type usually use low-resolution grids and idealized mixing processes (e.g., Pasquero and Emanuel 2008; Sriver and Huber 2010). Global lowresolution models provide reasonable estimates of heat transport in the ocean, but they cannot represent the complexity of TC-induced processes. Specifying realistic TC distributions on a low-resolution grid is a major challenge in itself. Therefore, regional high-resolution studies would offer a good alternative. To our knowledge, this has not yet been attempted.

Using a state of the art, primitive equations, regional oceanic model, the present study investigates the various processes by which extreme winds associated with cyclones influence the oceanic heat budget and impose their residual effect. The study area is located in the southwest Pacific and encompasses the South Pacific convergence zone (SPCZ; Vincent et al. 2011). The SPCZ is one of the most intense atmospheric convergence zones of the world and a major cyclogenesis area: $10 \%-15 \%$ of global cyclogenesis occurs in this region. To account for the extreme winds that must force the ocean model, we use a 25 -yr simulation with a regional mesoscale atmospheric model that realistically simulates TC distributions in the South Pacific (Jourdain et al. 2011). The adopted methodology consists of comparing twin oceanic experiments that are distinct by the presence or absence of extreme wind forcing in TCs. Using heat budget equations and analyzing the three-dimensional (3D) tendencies that explain TC-induced temperature changes, we provide an exhaustive quantification of physical processes responsible for oceanic heat changes along each cyclone track and over the whole region. After detailing 
the methodology and the model validation at event and climatological scales (sections 2 and 3), we examine the ocean heat budget associated with a composite of all cyclones and finally expand to the ocean climatology of the South Pacific (section 4).

\section{Materials and methods}

\section{a. The regional ocean model}

The ocean model configuration uses the Regional Oceanic Modeling System (ROMS; Shchepetkin and McWilliams 2005) in its nested version (Penven et al. $2006)$ over the southwest Pacific region $\left(8^{\circ}-30^{\circ} \mathrm{S}, 140^{\circ} \mathrm{E}-\right.$ $\left.170^{\circ} \mathrm{W}\right)$. It has 41 terrain-following vertical levels with $2-$ $5-\mathrm{m}$ vertical resolution in the first $50 \mathrm{~m}$ of the surface and then 10-20-m resolution in the thermocline and 200$1000-\mathrm{m}$ resolution in the deep ocean. The horizontal resolution is $1 / 3^{\circ}$, and the baroclinic time step is $1 \mathrm{~h}$; hourly outputs are stored for a case study and 1-dayaveraged outputs are stored for long-term analysis.

The turbulent vertical mixing parameterization is based on the scheme proposed by Large et al. (1994), featuring a $K$-profile parameterization (KPP) for the planetary boundary layer connected to an interior mixing scheme (see appendix for details). The boundary layer depth (h) varies with surface momentum and buoyancy forcing and is determined by comparing a bulk Richardson number to a critical value. The surface layer above the oceanic boundary layer obeys the similarity theory of turbulence. At the base of the boundary layer, both diffusivity and its gradient are forced to match the interior values. Below the boundary layer, vertical mixing is regarded as the superposition of three processes: vertical shear, internal wave breaking, and convective adjustment. The KPP model has been shown to accurately simulate processes such as convective boundary layer deepening, diurnal cycling, and storm forcing: it is widely used in ocean modeling (e.g., Halliwell et al. 2011). The model has also shown a reasonable level of accuracy in modeling TCinduced mixing (Jacob and Shay 2003). Some processes are nevertheless missing in this parameterization: for example, mixed layer instabilities that would further help the restratification process in the TC wake (Boccaletti et al. 2007) are neither resolved in our $1 / 3^{\circ}$-resolution model nor parameterized (for tropical applications, see also Marchesiello et al. 2011).

Open boundary conditions are treated using a mixed active/passive scheme (Marchesiello et al. 2001) that forces large-scale information from the Nucleus for European Modeling of the Ocean (NEMO) $1 / 2^{\circ}$ global model simulation (described in Couvelard et al. 2008) while allowing anomalies to radiate out of the domain.
The use of similar ROMS configurations in the southwest tropical Pacific region is largely validated through studies demonstrating skills in simulating both the surface (Marchesiello et al. 2010) and subsurface ocean circulation (Couvelard et al. 2008).

\section{b. TC forcing in twin ocean experiments}

The present oceanic configuration mainly differs from Marchesiello et al. (2010) by the atmospheric forcing. To compute the momentum fluxes, we use the 1979-2003 6-hourly outputs of atmospheric fields from a Weather Research and Forecasting model (WRF) simulation of the South Pacific climate (Jourdain et al. 2011). The simulation uses a two-way nested configuration forced at the lateral boundaries by the National Centers for Environmental Prediction/Department of Energy Global Reanalysis 2 (NCEP-2; Kanamitsu et al. 2002). The parent domain at $105-\mathrm{km}$ resolution spans the Indo-Pacific region $\left(42^{\circ} \mathrm{S}-25^{\circ} \mathrm{N}, 95^{\circ} \mathrm{E}-115^{\circ} \mathrm{W}\right)$, and the child domain at $35-\mathrm{km}$ resolution fully encompasses the SPCZ region $\left(2^{\circ}-\right.$ $\left.32^{\circ} \mathrm{S}, 139^{\circ} \mathrm{E}-161^{\circ} \mathrm{W}\right)$. The modeled large-scale environment and TC activity are validated and analyzed in detail in Jourdain et al. (2011). The large-scale SPCZ behavior, including both seasonal and interannual variability, and the statistical distribution of TC activity (genesis and occurrence) are in good agreement with observations. Jourdain et al. (2011) noted, however, a shift of TC intensity distribution toward more frequent occurrence of weaker cyclones (a known bias of medium-resolution models). All modeled TCs are identified via a cyclone tracker, which will be used again in the present study. Over the 1979-2003 period, our atmospheric simulation presents 235 TCs $\left(10-\mathrm{m}\right.$ wind speed reaching $17 \mathrm{~m} \mathrm{~s}^{-1}$ in 6-hourly outputs) including 55 TCs reaching at least $33 \mathrm{~m} \mathrm{~s}^{-1}$. The most extreme cyclones are absent from this model solution, but they do represent a small fraction of the total number. More importantly perhaps, the model provides a coherent set of TC events with a realistic development process (genesis and intensification stages). In addition, the large number of simulated cyclones in the atmospheric forcing allows a statistically robust representation of the oceanic response.

We purposely choose to focus here on the oceanic response to TC momentum forcing, which is assumed to be of primary importance. A more complete acknowledgment of TC forcing would require a representation of coupling processes involving the feedback of ocean temperatures (e.g., Lloyd and Vecchi 2011), wind waves, and sea spray (Bao et al. 2000) to TC formation and development. This will be explored in further studies. The 6-hourly momentum forcing of the ocean model is computed using wind fields from the WRF simulation; it is converted into stresses using the drag formulation of 
Powell et al. (2003) that parameterizes the drag reduction observed under extreme wind conditions. Surface freshwater and heat fluxes are computed using bulk formulations (Marchesiello et al. 2010) with large-scale air temperature, wind speed, and relative humidity from NCEP-2 data. TC winds do not enter the formulation of turbulent fluxes at the air-sea interface and TC forcing can only proceed by mechanical action of the wind stress (and its curl). Yet, negative feedbacks of SST perturbation on latent and sensible heat fluxes are permitted, but not on the outward longwave radiation (NCEP-2 SST values are used in this case). These choices underestimate the negative feedback of the ocean to TC-induced forcing: that is, one that would minimize the oceanic response to TCs. However, our results will show that only the strongest TC events appear to overestimate the oceanic response and that these events only weakly affect the overall cyclone effect. The simulation that includes TC wind forcing is referred to as the cyclone experiment in the following.

To assess the oceanic impact of extreme winds associated with cyclones, a twin simulation with "cyclone free" atmospheric forcing is designed (the no-cyclone experiment). Note that the term "cyclone free" does not indicate here the absence of cyclones but the absence of the extreme winds associated with them. The cyclonefree forcing field is computed by saturating wind stress intensity at $0.1 \mathrm{~N} \mathrm{~m}^{-2}$ (which corresponds to a maximum surface wind speed of about $13 \mathrm{~m} \mathrm{~s}^{-1}$ ) while preserving wind stress directions, within a $6^{\circ}$ radius disc around each point of the cyclone tracks. The value of $0.1 \mathrm{~N} \mathrm{~m}^{-2}$ was chosen as the maximum climatological wind stress during summer in that region. It seemed reasonable to assume that such a threshold would prevent any major effect of cyclones while preserving their large-scale environment. Note that the TC removal procedure does not affect any other high wind event that can escape the cyclone tracker. Figure 1 shows an example of the resulting wind forcing in the cyclone and no-cyclone experiments for a strong TC. Only the extreme winds are removed, but the largescale wind pattern remains unchanged. It may be questioned whether the weak large-scale cyclonic vortex that remains around the cyclone core should also be removed. Our understanding is that they participate in low numbers to the activity of numerous tropical storms that populate the cyclogenesis area. It is also consistent with the virtual reality of a cyclone-free world where storms do not get to become cyclones. In the following, TCinduced oceanic anomalies are assessed by analyzing the differences between the twin ocean experiments.

\section{c. Temperature equation and tendencies}

To characterize the processes responsible for temperature anomalies, the heat budget is computed. The
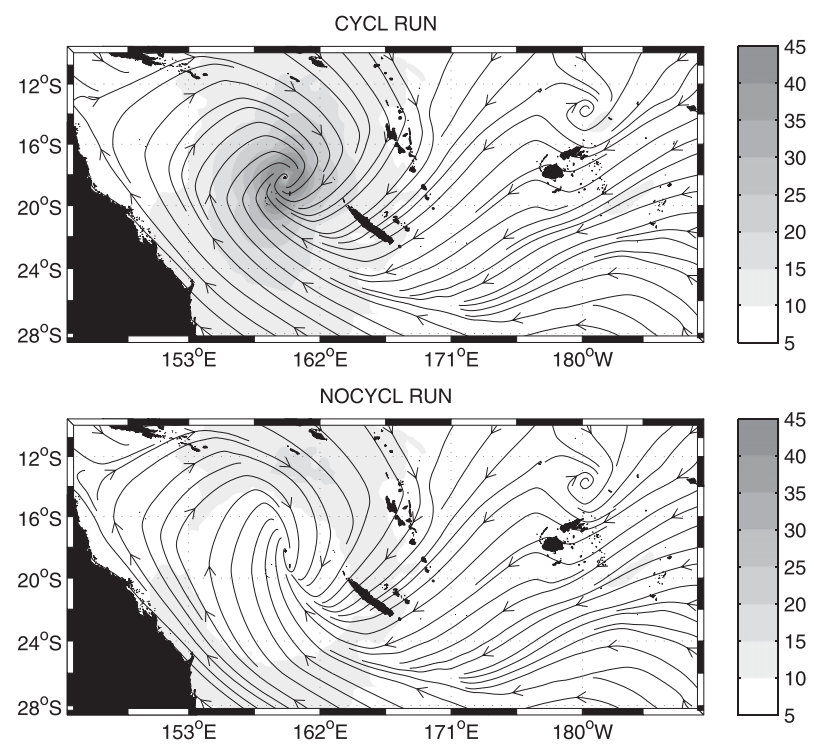

FIG. 1. Snapshots of WRF surface wind intensity (shading; $\mathrm{m} \mathrm{s}^{-1}$ ) and streamlines. (a) A typical cyclone used as forcing for the reference ROMS ocean simulation (the cyclone experiment). (b) Extreme wind speeds are removed from the TC winds and the remaining field is used as forcing for the ocean simulation (the nocyclone experiment). A wind stress threshold of $0.1 \mathrm{~N} \mathrm{~m}^{-2}$ is used to clip extreme winds within a $6^{\circ}$ disk radius of the cyclone center.

full three-dimensional temperature equation of the interior ocean is

$$
\begin{aligned}
\underbrace{\partial_{t} T}_{\text {RATE }}= & \underbrace{-u \partial_{x} T-v \partial_{y} T}_{\text {HADV }} \underbrace{-w \partial_{z} T}_{\text {VADV }}+\underbrace{D_{l}(T)}_{\text {HMIX }} \\
& +\underbrace{D_{z}(T)}_{\text {VMIX }}+\underbrace{I(z)}_{\text {FORC }},
\end{aligned}
$$

with the following surface boundary condition:

$$
\left(k_{z} \partial_{z} T\right)_{z=0}=\frac{Q^{*}+Q_{s}}{\rho_{0} C_{p}},
$$

where $T$ is the model potential temperature; $(u, v, w)$ are the components of ocean currents; $D_{l}(T)$ is the lateral diffusion operator; $D_{z}(T)=\partial_{z}\left(k_{z} \partial_{z} T\right)$ is the vertical diffusion operator with $k_{z}$ being the vertical diffusion coefficient; and $I(z)=\left(Q_{s} / \rho_{0} C_{p}\right) \partial_{z} f(z)$ is the heating rate due to the penetrative solar heat flux with $Q_{s}$ being the net surface solar heat flux and $f(z)$ being the attenuation factor that determines the fraction of solar radiation that reaches depth $z$. Here, $Q^{*}$ contains the other surface heat flux terms: longwave radiation and latent and sensible heat fluxes $\left(Q^{*}\right.$ and $Q_{S}$ are positive when directed downward: i.e., warming the ocean). A proxy for the SST equation is derived by averaging Eq. (1) over the time-varying mixed layer depth $h$ (Menkes et al. 2006), 

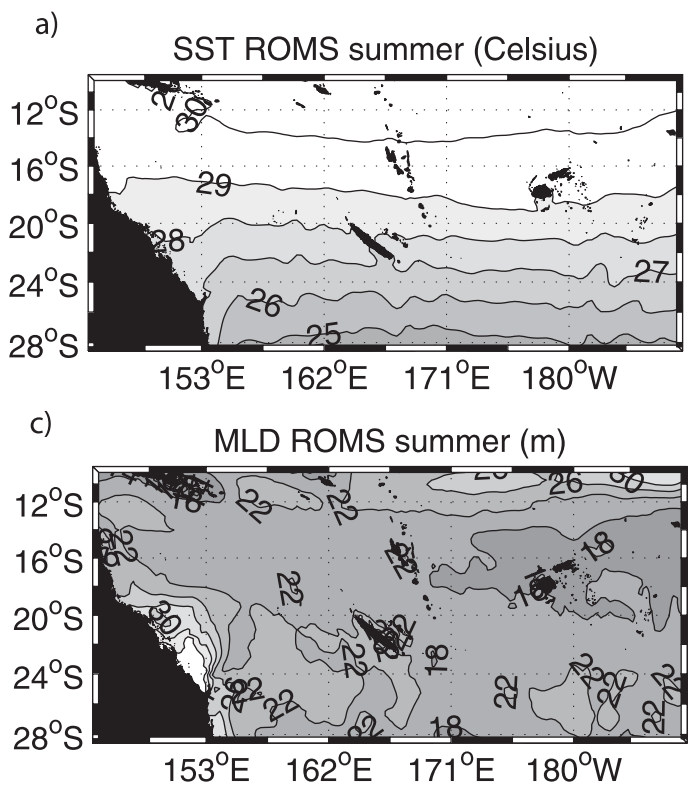
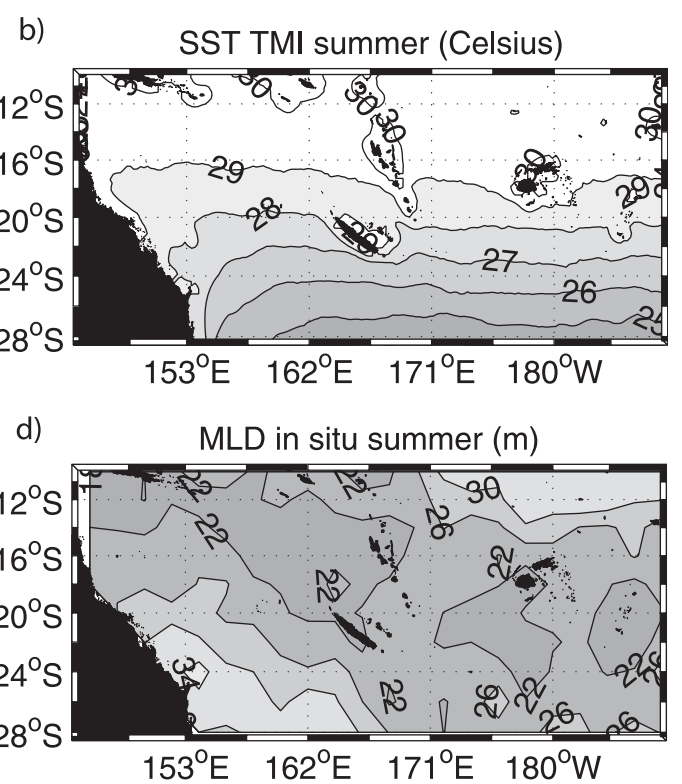

FIG. 2. (top) Mean austral summer [January-March (JFM)] SST $\left({ }^{\circ} \mathrm{C}\right)$ from (a) the 1979-2003 ROMS control run and (b) the TMI-AMSR-E 1998-2009 data (http://www.ssmi.com/sst/microwave_oi_sst_data_description.html). (bottom) Mean summer (JFM) mixed layer depth from (c) 1979-2003 ROMS control run and (d) climatology from De Boyer Montégut et al. (2004) (http://www.locean-ipsl.upmc.fr/ cdblod/mld.html).

$$
\begin{aligned}
\underbrace{\partial_{t} S S T}_{\text {RATE }}= & \underbrace{-\left\langle u \partial_{x} T+v \partial_{y} T\right\rangle}_{\text {HADV }} \underbrace{-\left\langle w \partial_{z} T\right\rangle}_{\text {VADV }} \\
& +\underbrace{\left\langle D_{l}(T)\right\rangle}_{\text {HMIX }}+\underbrace{\frac{Q^{*}+Q_{s}[1-f(z=-h)]}{\rho_{0} C_{p} h}}_{\text {FORC }} \\
& -\underbrace{\frac{\left(k_{z} \partial_{z} T\right)(z=-h)}{h}-\frac{1}{h} \partial_{t} h[\mathrm{SST}-T(z=-h)]}_{\text {VMIX }} .
\end{aligned}
$$

Brackets denote the vertical average over the mixed layer depth $h$ (with our notation, $h$ is positive): $\langle x\rangle=$ $(1 / h) \int_{-h}^{0} x d z$. Here, RATE is the rate of change (or temporal tendency) of SST; HADV is lateral advection; VADV is vertical advection; HMIX is lateral diffusion; FORC is the heat input by surface forcing in the mixed layer with $Q^{*}$ the nonsolar heat flux; and VMIX is the heat input through the mixed layer base by vertical mixing [we define here vertical mixing as the combination of entrainment/detrainment and local (downgradient) vertical diffusion at the mixed layer base]. The mixed layer depth is calculated as the depth at which density is $0.01 \mathrm{~kg} \mathrm{~m}^{-3}$ greater than surface density, as in Menkes et al. (2006). This criterion is in the range of those reported in the literature (for a detailed discussion, see De Boyer Montégut et al. 2004). SST is used interchangeably with mixed layer temperature in the following. The various
SST budget terms, as well as all model state variables, are 1-day averaged. Three layers are defined in the following: the surface layer from the surface to the mixed layer $(\sim 0-30 \mathrm{~m})$; the subsurface layer below the mixed layer ( 30-100 m); and the deep layer (below $100 \mathrm{~m}$ ).

\section{Validation of the ocean model with WRF forcing}

The climatological ocean circulation and its validation are detailed in Couvelard et al. (2008) and Marchesiello et al. (2010). Here, we focus on temperature during the austral summer, which is the cyclone season. The SST pattern agrees well with observations (Figs. 2a,b) having a realistic north-south gradient, although a $1^{\circ} \mathrm{C}$ warm model bias is apparent in the warm pool region. Coastal cooling associated with the East Australian Current is also not properly resolved (Couvelard et al. 2008). The mixed layer depth (Figs. 2c,d) shows good agreement with in situ observations (De Boyer Montégut et al. 2004) in the TC occurrence region. The vertical structure of summer temperature is illustrated in Fig. 3; it is also close to observations, despite the already mentioned warm bias in the surface warm pool, but this area is rarely impacted by TCs. These brief validations indicate that the WRF atmospheric wind forcing leads to a relevant representation of the mean ocean structure.

More importantly, the modeled ocean response to TC forcing is validated in Fig. 4. It is performed by extracting SST from the cyclone experiment along all 
a)

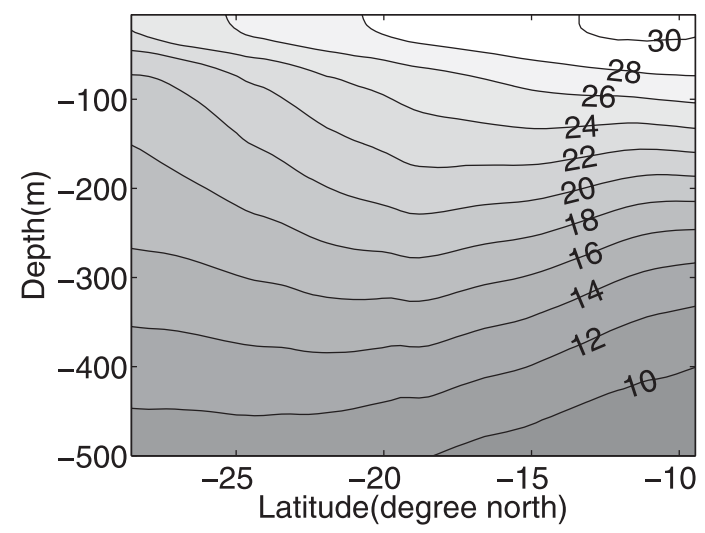

b)

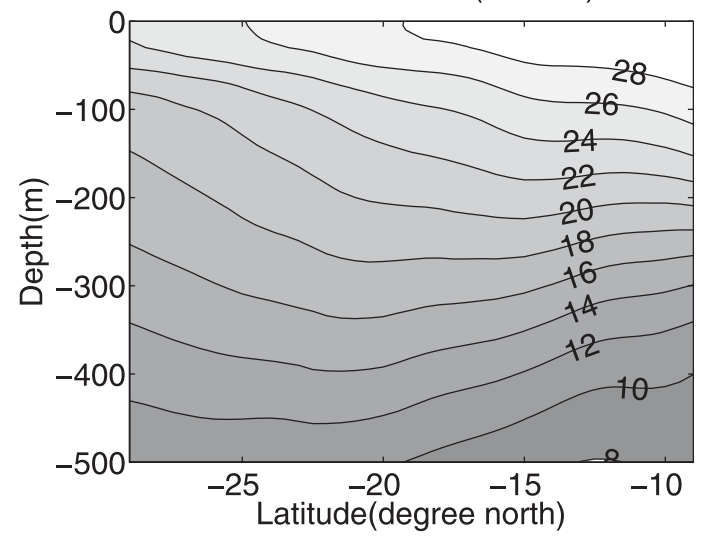

FIG. 3. Zonally averaged vertical section of JFM temperature $\left({ }^{\circ} \mathrm{C}\right)$ from (a) the 1979-2003 ROMS control run and (b) Commonwealth Scientific and Industrial Research Organisation (CSIRO) Atlas of Regional Seas (CARS) data (http://www.marine.csiro.au/ dunn/cars2006).

cyclone tracks from 10 days before to 30 days after the cyclone passage. A similar extraction is performed in the Tropical Rainfall Measuring Mission (TRMM) Microwave Imager (TMI)-Advanced Microwave Scanning Radiometer for Earth Observing System (EOS) (AMSRE) dataset (http://www.ssmi.com/sst/microwave_oi_sst_ data_description.html) from 1998 to 2007 along the observed cyclone tracks from IbTrack dataset (http:// www.ncdc.noaa.gov/oa/ibtracs). For both the model and the observations, the seasonal cycle is removed by subtracting the daily climatology. To illustrate the effect of TCs, we first estimate the prestorm SST value at each point of a cyclone track by taking the averaged SST between days -10 and -2 . Then, we calculate for each cyclone and at each point along the track the difference between the SST at any given time between days -10 and +30 and its prestorm value. This procedure provides SST anomalies for both the model and the observations.

The timing of the modeled SST response to TCs is in excellent agreement with observations, but the intensity of the response is weaker in the model by about $50 \%$ (Fig. 4a). Nevertheless, the SST spread around the mean value is similar in the model and observations, suggesting that the model is able to capture the diversity of oceanic response. A separation using the southwest Pacific TC intensity scale ${ }^{1}$ (Fig. 4c) shows that the model SST anomaly (bold curve) is largely dominated by the numerous

\footnotetext{
${ }^{1}$ The southwest Pacific TC intensity scale (the same as the Australian TC intensity scale) measures tropical cyclones using a five-category system for winds in the ranges of $17-24 \mathrm{~m} \mathrm{~s}^{-1}$; 24-33 $\mathrm{m} \mathrm{s}^{-1} ; 33-44 \mathrm{~m} \mathrm{~s}^{-1}$; and 44-55 $\mathrm{m} \mathrm{s}^{-1}$, respectively. Categories 3-5 are hurricanes in the Saffir-Simpson scale.
}

weaker TCs (categories 1-2: wind speed between 17 and $33 \mathrm{~m} \mathrm{~s}^{-1}$; thin curve). In comparison with the TMIAMSR-E dataset (Fig. 4d), the model seems to underestimate the cooling produced by those weaker cyclones (thin curve). Our understanding is that cooling underestimation is due to the use of large-scale (NCEP-2) atmospheric data to compute surface fluxes, which misses TC-induced latent heat fluxes. However, the model response seems to improve when only considering cyclones that are strong enough to produce significant cooling (anomalies lower than $-0.5^{\circ} \mathrm{C}$ at day 2; see Fig. $4 \mathrm{~b}$ ). In this case, the match with observations becomes very good, suggesting that cyclones with the largest effect are properly represented in the model. Interestingly, further in the intensity scale we see that cooling by the model's strongest cyclones (categories 3-4: 33-50 $\mathrm{m} \mathrm{s}^{-1}$; dashed curve in Fig. 4c) is overestimated. Their cooling effect is even larger than observed with category-5 TCs (Fig. 4d; wind speed greater than $50 \mathrm{~m} \mathrm{~s}^{-1}$ : not represented in the model). However, it appears that strong cyclones are too rare to produce any significant impact on the composited SST. Nevertheless, the reason for overestimating their individual effect may be associated with air-sea coupling. The latter should provide significant negative feedback to the strong TCs (much less in weaker ones). It can thus be expected that a forced simulation would overestimate the lifetime of stronger TCs and therefore their SST cooling effect. However, for now we can only advance this as conjecture, pending coupled simulations to check its validity. Note, finally, that the bias associated with wind filtering method in the no-cyclone experiment is evaluated in Fig. $4 \mathrm{c}$ and appears to be very small. Overall, these comparisons give us confidence in the model's ability to simulate a statistically robust oceanic response to cyclones. 
a)

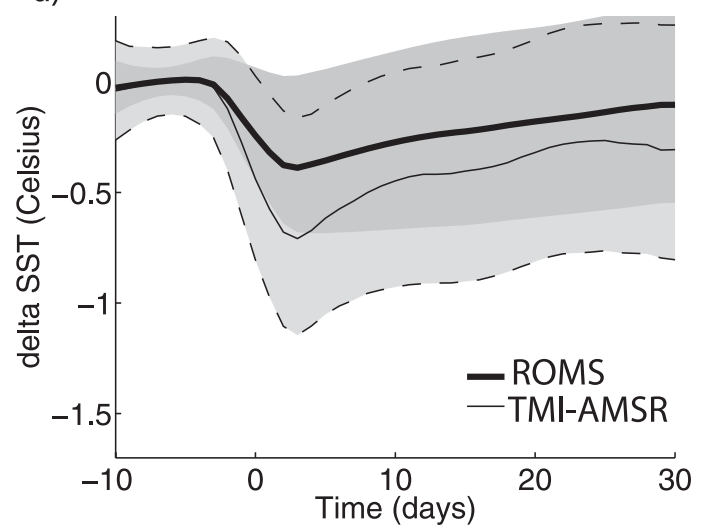

c)

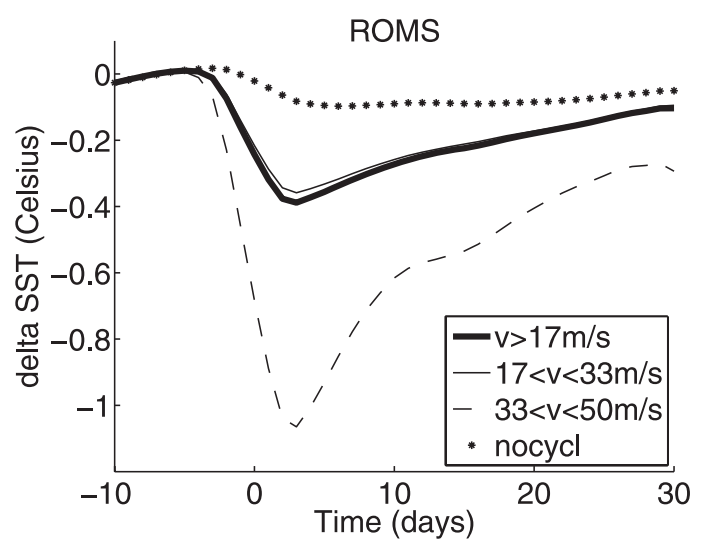

b)

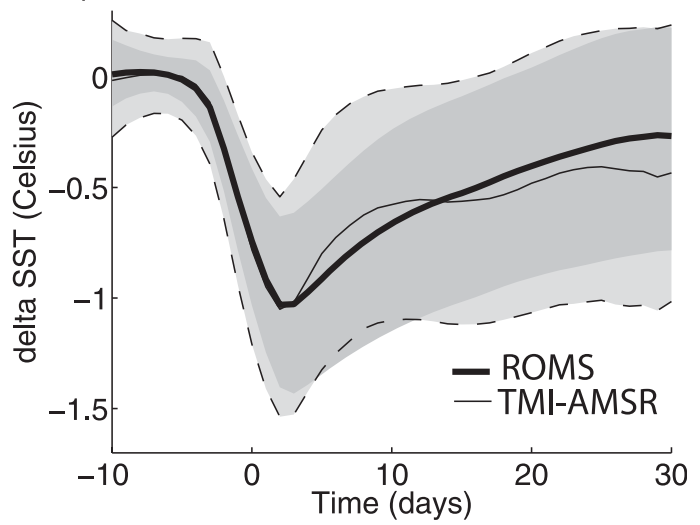

d)

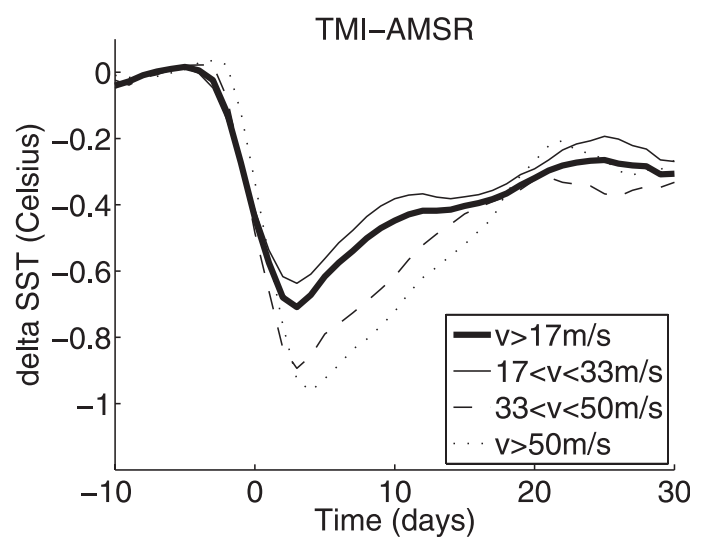

FIG. 4. (a),(b) The SST cooling anomaly $\left({ }^{\circ} \mathrm{C}\right)$ of a composited cyclone wake (over $2^{\circ}$ radius) as a function of time relative to cyclone occurrence in the 1979-2003 model simulation (black bold line) and in the TMI-AMSR-E 19982007 data (black thin line). The SST anomaly is calculated as the difference between the SST at time $t$ and its prestorm value (average over the period from day -10 to day -2 ). In (a) all cyclones are considered and in (b) only those producing a cooling lower than $-0.5^{\circ} \mathrm{C}$ at day 2 are considered. The dark gray shading (light gray with dashed lines) represents the limits of the upper and lower quartiles of the ROMS (TMI-AMSR-E) SST distribution. (c) The 19792003 model simulation and (d) the TMI-AMSR-E dataset SST cooling anomaly $\left({ }^{\circ} \mathrm{C}\right)$ for various TC categories: all TC winds stronger than $17 \mathrm{~m} \mathrm{~s}^{-1}$ (bold solid line), TC winds between 17 and $33 \mathrm{~m} \mathrm{~s}^{-1}$ (thin solid line), TC winds between 33 and $50 \mathrm{~m} \mathrm{~s}^{-1}$ (dashed line), and TC winds stronger than $50 \mathrm{~m} \mathrm{~s}^{-1}$ (dotted line). Stars in (c) represent the residual SST anomaly of the cyclone-free experiment (i.e., an error estimate of our method for computing TCinduced thermal anomalies).

\section{Results}

\section{a. Case studies}

The oceanic response to three selected TC events of the WRF solution is illustrated in Fig. 5 and Table 1. The cyclones are labeled TC1 (January 1979), TC2 (western event during December 1981), and TC3 (eastern event during December 1981). Anomalies, calculated as differences between the cyclone and no-cyclone experiments, are composited along the cyclone track at each 6-h location over a $6^{\circ}$ radius disk. If successive disks overlap, the largest anomalies between overlapping points are retained. TC-induced SST cooling appears usually much stronger at the track center and on its left side (with reference to the cyclone motion which is southward) than on its right side (Figs. 5a,b). In the following, the left (right) side is referred to as strong (weak) side. This asymmetry is well known and has been usually attributed to enhanced vertical mixing in the storm's strong side (Chang and Anthes 1978; Pudov et al. 1979; Price 1981; Sanford et al. 2007; Samson et al. 2009). It partly results from enhanced wind speed on this particular side due to the translation speed of the storm (Figs. 5g,h); TC2 is the strongest of the three TCs and also the slowest one (see Table 1) moving at $1.75 \mathrm{~m} \mathrm{~s}^{-1}$ when it reaches category 4 . These combined characteristics produce the strongest cooling, reaching $-4^{\circ} \mathrm{C}$, but with a rather modest bias on the strong side, consistent with the cyclone's slow 
JANUARY 1979

a)

$\triangle$ SST (Celsius)

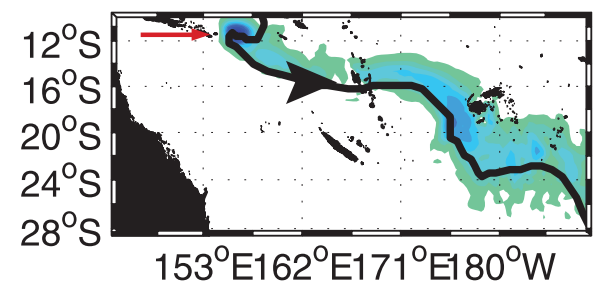

c)

$\Delta^{T}$ at $65 \mathrm{~m}$ (Celsius)

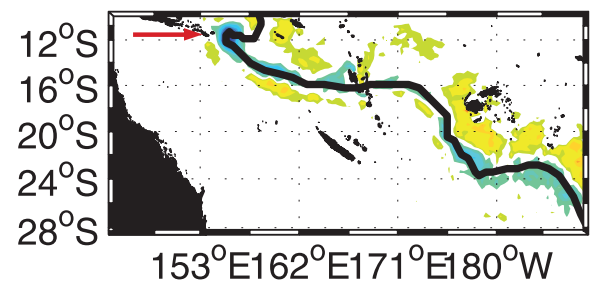

e)

$53^{\circ} \mathrm{E} 162^{\circ} \mathrm{E} 171^{\circ} \mathrm{E} 180^{\circ} \mathrm{W}$

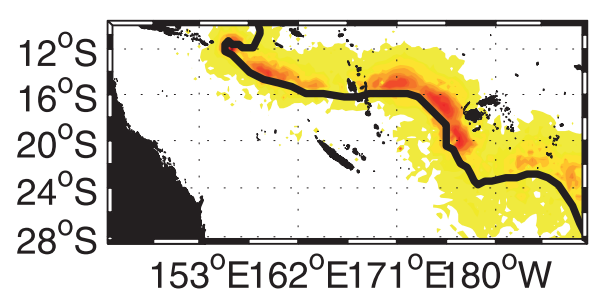

g) $\Delta$ Wind stress $(\mathrm{N} / \mathrm{m} 2)$

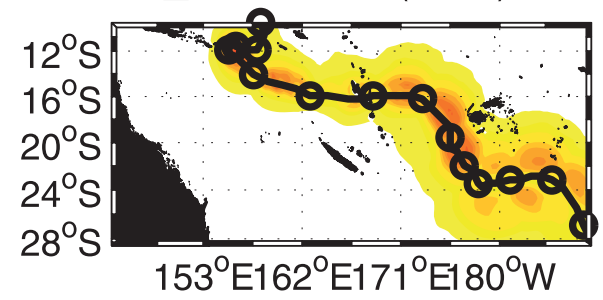

b)

DECEMBER 1981

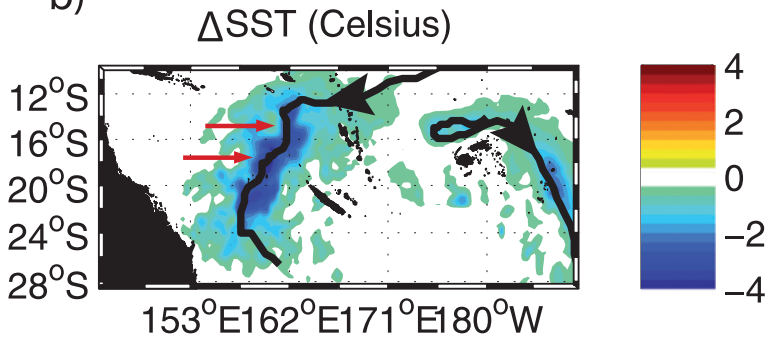

d)

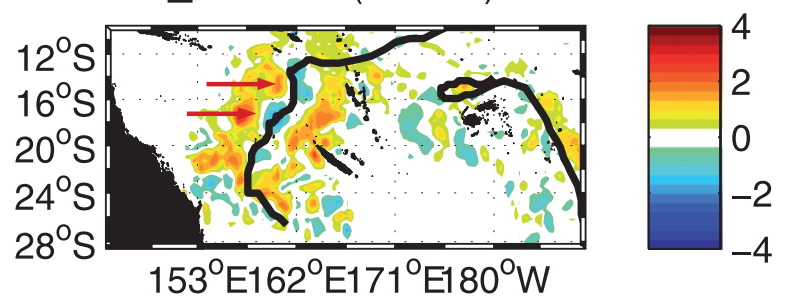

f)

$153^{\circ} \mathrm{E} 162^{\circ} \mathrm{E} 171^{\circ} \mathrm{E} 180^{\circ} \mathrm{W}$

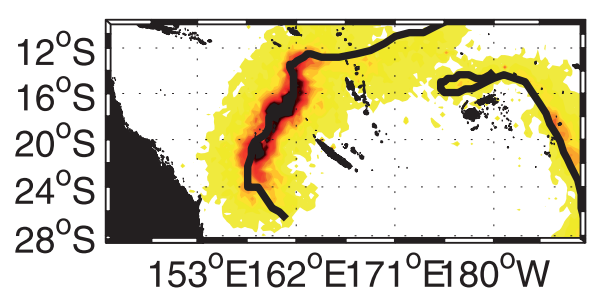

h) $\quad \Delta$ Wind stress $(\mathrm{N} / \mathrm{m} 2)$

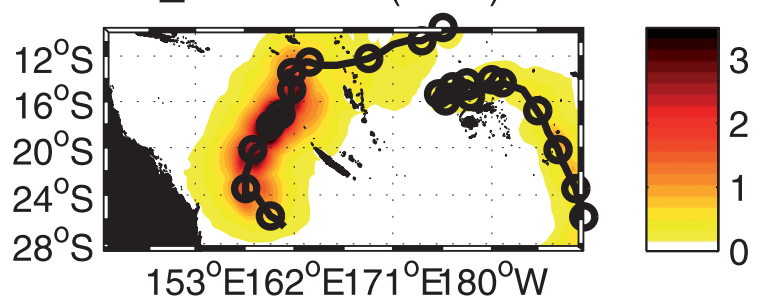

FIG. 5. TC-induced anomalies for three typical cyclones (tracks in black lines) in (left) January 1979 (TC1) and (right) December 1981 (TC2 and TC3). (a),(b) SST $\left({ }^{\circ} \mathrm{C}\right)$; (c),(d) temperature at $65 \mathrm{~m}\left({ }^{\circ} \mathrm{C}\right)$; (e), (f) vertical diffusivity $\left(\mathrm{m}^{2} \mathrm{~s}^{-1}\right)$; and $(\mathrm{g}),(\mathrm{h})$ wind stress $\left(\mathrm{N} \mathrm{m}^{-2}\right)$. Circles represent the daily position of cyclones. Black arrows represent the TC motion direction. At each track point, anomalies during the cyclone passage are shaded over a $6^{\circ}$ radius. Red arrows point to locations where Froude numbers are less than unity (subcritical translation speed).

motion (Fig. 5b). The two other TCs moving faster exhibit a larger leftward bias than TC2 because of their faster motions (Figs. 5a,b and Table 1). A confirmation of the role played by vertical mixing in the surface oceanic response is the good match between spatial patterns of surface cooling and vertical diffusivity $K_{z}$ anomaly at the mixed layer base (cf. Figs. 5a,b and cf. Figs. 5e,f). Wind stress anomalies (Figs. 5g,h) also match extremely well the pattern and intensity of vertical mixing.

The role played by near-inertial currents in sheardriven mixing has long been recognized (e.g., Chang and
Anthes 1978). Near-inertial motions are a nonstationary response to the moving storm and are promoted by strong, fast-moving storms: that is, with a smaller time scale than the inertial period (IP; Froude number greater than 1; Greatbatch 1983). Following Jaimes and Shay (2009), we computed the Froude number Fr as the ratio between the TC translation speed $U_{h}$ and the phase speed of NIOs first baroclinic mode $c_{1}$,

$$
\operatorname{Fr}=\frac{U_{h}}{c_{1}}, \quad \text { with } \quad c_{1}^{2}=g\left(\frac{\rho_{2}-\rho_{1}}{\rho_{2}}\right) \frac{h_{1} h_{2}}{h_{1}+h_{2}},
$$


TABLE 1. Parameters of three simulated TCs: TC wind speed $W\left(\mathrm{~m} \mathrm{~s}^{-1}\right)$; TC translation speed $U_{h}\left(\mathrm{~m} \mathrm{~s}^{-1}\right)$; velocity of the first baroclinic mode of NIOs $c_{1}\left(\mathrm{~m} \mathrm{~s}^{-1}\right)$; Froude number $\left(\mathrm{Fr}=U_{h} / c_{1}\right)$; IP $(\mathrm{h})$; and the wavelength $L$ (given as $\left.U_{h} \mathrm{IP} ; \mathrm{km}\right)$. Average and extreme values over the tracks are given.

\begin{tabular}{|c|c|c|c|c|c|c|}
\hline & $W\left(\mathrm{~m} \mathrm{~s}^{-1}\right)$ & $U_{h}\left(\mathrm{~m} \mathrm{~s}^{-1}\right)$ & $c_{1}\left(\mathrm{~m} \mathrm{~s}^{-1}\right)$ & $\mathrm{Fr}$ & IP (h) & $L(\mathrm{~km})$ \\
\hline TC1 average & 26.5 & 4.5 & 1.8 & 2.6 & 51.9 & 805 \\
\hline $\mathrm{TC} 1$ extrema & $17.6-37.2$ & $1.1-8.7$ & $0.9-2.2$ & $0.6-7.5$ & $24.4-173.3$ & $193-2363$ \\
\hline TC2 average & 30.7 & 3.9 & 1.9 & 2.1 & 53.0 & 653 \\
\hline TC2 extrema & $17.1-44.1$ & $1.1-8.0$ & $0.9-2.3$ & $0.5-4.0$ & $26.8-96.4$ & $158-1564$ \\
\hline TC3 average & 24.0 & 4.5 & 1.8 & 2.8 & 41.6 & 516 \\
\hline TC3 extrema & $18.3-27.1$ & $1.8-7.2$ & $0.8-2.1$ & $1.2-8.7$ & $24.8-49.4$ & $128-899$ \\
\hline
\end{tabular}

where $h_{1}$ is the $20^{\circ} \mathrm{C}$ isotherm depth (proxy for the thermocline); $h_{2}$ is the thickness of the layer extending from $h_{1}$ down to $1000 \mathrm{~m}$; and $\rho_{1}$ and $\rho_{2}$ are vertically averaged densities upon $h_{1}$ and $h_{2}$, respectively. Froude numbers exceeding unity are typically associated with a translation speed greater than $1-2 \mathrm{~m} \mathrm{~s}^{-1}$. These numbers for our three selected case studies are given in Table 1. In all cases, their average values are greater than 1 , indicating a predominant near-inertial response. However, at some locations (pointed to by the red arrows in Fig. 5), TC1 and TC2 have subcritical translation speeds $(\mathrm{Fr}<1)$, suggesting a more dominant stationary signature of the wind stress curl, expressed as Ekman pumping ${ }^{2}$ near the TC center (as opposed to nonstationary inertial pumping). To extend this discussion to the more general case, the probability density function (PDF) of Froude numbers based on all simulated events is given in Fig. 6. It shows that most cyclones along their tracks have supercritical translation speeds. This result confirms the ubiquity of near-inertial response in TC wakes, which are prone to vertical shear instability. However, as will be seen by examining the heat budget (following sections), it is not inconsistent with Ekman pumping being a major player in TC-induced temperature anomalies. Note that IPs and wavelengths $L$ of TC-induced NIOs are also given in Table 1. With typical values of 1-2 days and $500 \mathrm{~km}$, respectively, they are well resolved by the model whose temporal and spatial resolutions are $1 \mathrm{~h}$ and $35 \mathrm{~km}$.

The subsurface thermal response (Figs. 5c,d) shows very different patterns compared with the surface, with both positive and negative anomalies for the three selected TCs. Consistent with its fast motion, TC1 induces a relatively weak negative anomaly of about $-1^{\circ} \mathrm{C}$ around the track center (but reaching $-4^{\circ} \mathrm{C}$ near Papua New

\footnotetext{
${ }^{2}$ In the linear theory, upwelling velocity from Ekman pumping is maximum at the base of the surface boundary layer then decreases linearly (e.g., McWilliams 2006); thus, it strongly participates in the surface thermal response by uplifting the thermocline (e.g., Price 1981; Shay et al. 2000).
}

Guinea, where it becomes subcritical; Fig. 5c, red arrow) and a weak positive anomaly on the left side, reaching $+1^{\circ} \mathrm{C}$ at $300 \mathrm{~km}$ off its track. With its slow motion, TC2 shows stronger cooling under its track (particularly where $\mathrm{Fr}<1$; Fig. 5d, red arrows) and stronger warming off its track, reaching $+3^{\circ} \mathrm{C}$ and extending to $600 \mathrm{~km}$ on both sides. TC3 presents weaker anomalies again, consistent with weaker winds and fast motion. The difference between SST and subsurface temperature anomaly patterns confirms that mechanisms other than mixing (e.g., upwelling) are significant as put forward by previous case studies. This is examined in the following sections using all events to provide statistical reliability.

The time evolution of subsurface ocean response to TC1 is illustrated in Fig. 7 at the location reached by the cyclone core on 13 January. Even before the passage of the cyclone's inner core, its outer winds can already inject mechanical energy into the ocean giving the effect of enhanced vertical mixing, a deepening of the mixed layer (Fig. 7a), and a slight warming of the ocean subsurface at 50-m depth (Fig. 7c). As the inner cyclone passes over the selected location, vertical mixing and mixed layer deepening reach their maxima (Fig. 7a). As the cyclone leaves the site, TC-induced upwelling associated with surface flow divergence (Ekman pumping) increases up to $80 \mathrm{~m} \mathrm{day}^{-1}$ (Figs. 7b,d). It results in strong vertical advection of subsurface waters that lifts the mixed layer base (Figs. 7a,c,d). Following the TC-induced upwelling, the currents in the wake become more near inertial after the first half-inertial period; their transport converges toward the storm track, which forces downwelling of the isotherms (and a slight deepening of the mixed layer). A near-inertial cycle of upwelling and downwelling (inertial pumping) then develops with speeds of 20-40 m day ${ }^{-1}$ in the thermocline (Figs. 7b,d). Once near-inertial motions are excited, their energy is radiated downward with an efficiency that depends on the geostrophic background flow (as their frequency is shifted by background relative vorticity; see Kunze 1985). They may even be trapped in the eddy field, enhancing surface or subsurface sheardriven mixing depending on the sign of background vorticity (Jaimes and Shay 2010). These typical features are 
a)

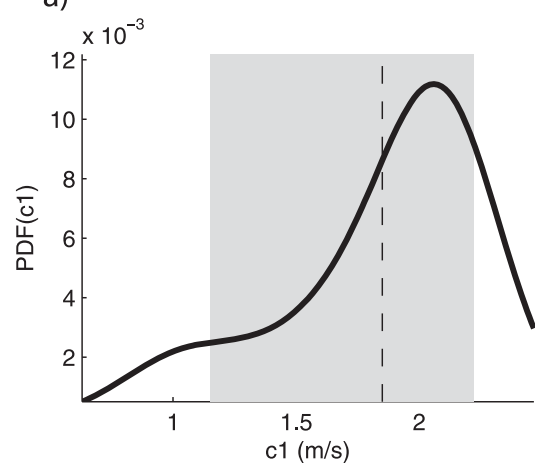

b)

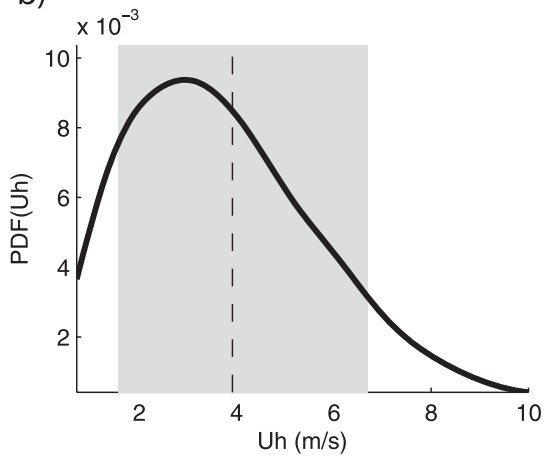

c)

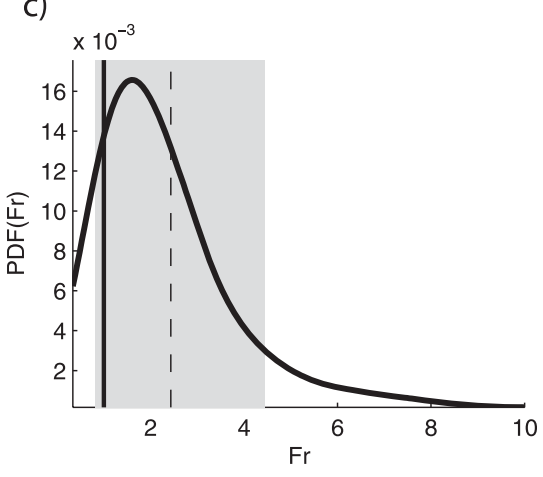

FIG. 6. PDFs over the whole cyclone simulation of the following parameters: (a) velocity of the first baroclinic mode of NIOs under TC tracks $\left(\mathrm{m} \mathrm{s}^{-1}\right)$, (b) TC translation speed $\left(\mathrm{m} \mathrm{s}^{-1}\right)$, and (c) TC Froude numbers. The shaded area represents the parameter distribution between the upper and lower 10th percentile marks; the dashed vertical line represents the parameters mean values.

similar to those described $30 \mathrm{yr}$ ago by Price (1981) and more recently by Jaimes and Shay (2010). They give us confidence in the model's ability to represent NIOs and shear-driven mixing, which are critical to reproducing the observed response to TCs.

\section{b. Composite analysis of TC wakes}

The previous section has illustrated the diversity of oceanic response to selected TC conditions and the time evolution of this response to a strong cyclone. The model is shown to reproduce observation of individual events. These validations allow us to turn to our main objective: an assessment of the mean balance of oceanic processes and regional climatic signature of tropical cyclones. To that end, we use 1-day averages of model variables and budget terms in which most near-inertial motions are filtered (NIOs are also filtered because of the compositing of many events in which their frequency varies according to background vorticity and latitude). In this section, a composite of all model TCs (235 cases) is presented. This will provide a generic oceanic response (only partially permitted by a selection of case studies) and present the cumulated effect of a realistic distribution of cyclones.

\section{1) Composite ANOMALIES UNDER THE CYCLONE}

A spatial distribution of surface and subsurface effects during TC occurrence is presented for all events (Fig. 8). Figure 8 is thus an extension of Fig. 5 for all cyclones. TC-induced anomalies are computed over $6^{\circ}$ radius disks at each 6-h TClocation. The maximum value is retained if two successive disks of the same TC overlap. The full map is then computed by averaging all the resulting tracks over the 25-yr simulation.

As expected, the overall effect of cyclones at the ocean surface is cooling (Fig. 8a). The observed patchiness is due to remaining undersampling of a nonrandom collection of cyclone tracks and would be reduced by a longer simulation. Nevertheless, the pattern is coherent and shows a mean TC-induced cooling of about $-1^{\circ} \mathrm{C}$, within the range of published estimates (e.g., Sriver and Huber 2007; Sriver et al. 2008). The spatial cooling pattern is strongly correlated with vertical diffusivity (Fig. 8c), with values as large as $0.035 \mathrm{~m}^{2} \mathrm{~s}^{-1}$ in intense cooling areas; diffusivity is itself strongly correlated with cyclone wind stress (Fig. 8d). Note that our modeled TCinduced diffusivities are about $50 \%$ stronger than those estimated in Sriver and Huber (2007). ${ }^{3}$

At $65 \mathrm{~m}$, which is below the mixed layer (Fig. 8b), the picture is quite different from that obtained with the assumption that subsurface anomalies are dominantly produced by wind-driven mixing (Sriver and Huber 2007). The same result can be seen in Fig. 5 for particular events with both positive and negative temperature anomalies along TC tracks. The composited subsurface pattern has a tendency to show slightly negative or nearzero anomalies north of $15^{\circ} \mathrm{S}$ and a slight warming south of $15^{\circ} \mathrm{S}$. This dipole pattern is also noticeable in Argo data and is linked to the competing vertical mixing and advection processes. Cooling by vertical advection has a deep signature and operates over the whole region, but vertical mixing is ineffective in the warm pool area (weak surface cooling and subsurface warming) because the thermocline is too deep for wind-driven mixing to reach there (see further in the text).

\footnotetext{
${ }^{3}$ Sriver and Huber (2007) estimate the annual-mean diffusivity attributable to TC mixing assuming that all mixing in a given year is achieved during the single largest cooling event calculated over a 24-h period. Thus, to compare with our Fig. 7c, we must multiply their diffusivity values by 365 . In the South Pacific, their annualmean value of $0.4 \mathrm{~cm}^{2} \mathrm{~s}^{-1}$ comes to $0.015 \mathrm{~m}^{2} \mathrm{~s}^{-1}$ at event time scale.
} 

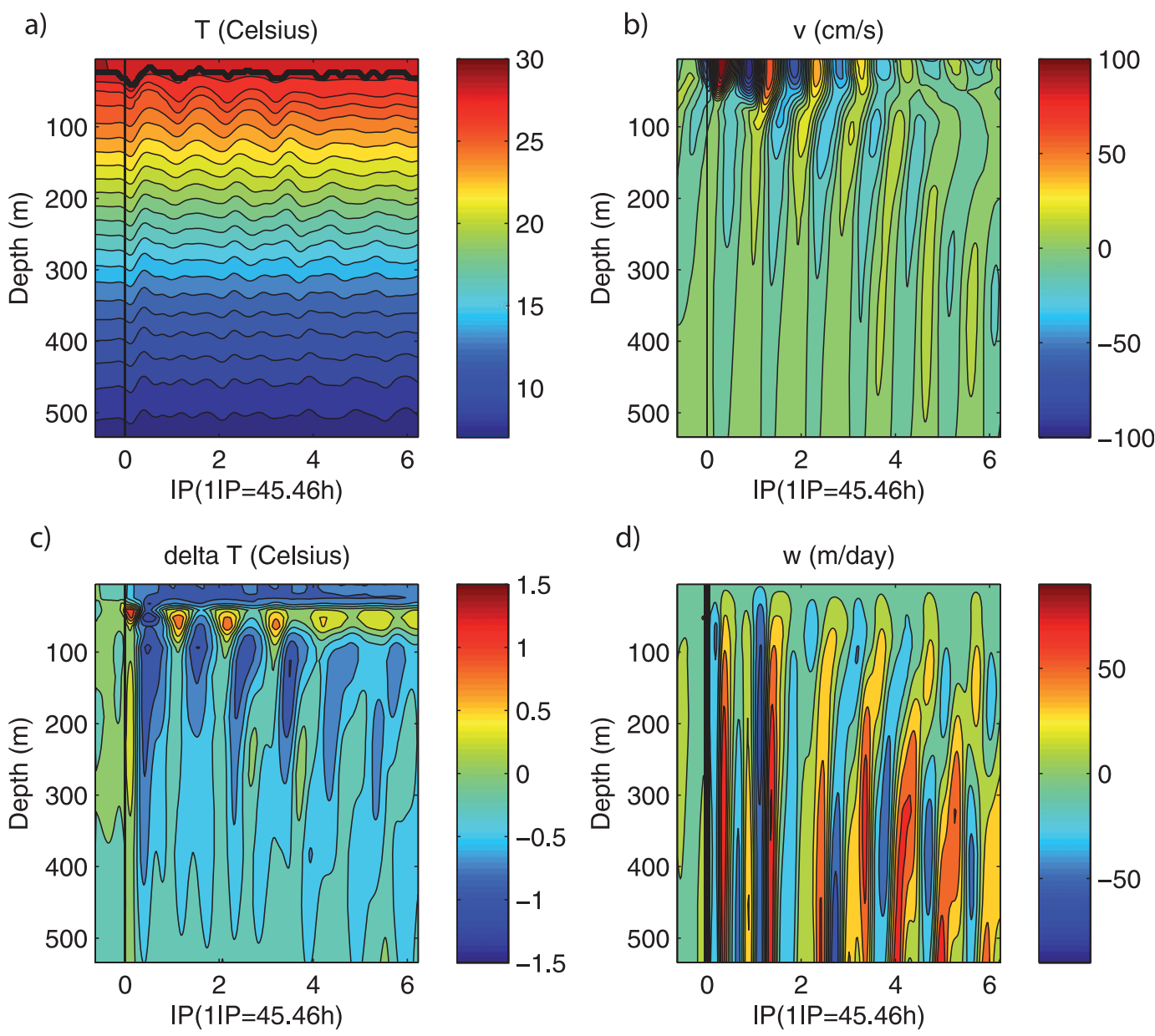

FIG. 7. Vertical profiles of fields extracted at the model time step $(1 \mathrm{~h})$ as a function of IP, at track location $15^{\circ} \mathrm{S}$, $163^{\circ} \mathrm{E}$ of cyclone TC1 (January 1979; Fig. 5). The vertical line denotes cyclone occurrence at the track location on 13 January. (a) Temperature $\left({ }^{\circ} \mathrm{C}\right)$; (b) meridional velocity $\left(\mathrm{cm} \mathrm{s}^{-1}\right)$; (c) temperature anomaly $\left({ }^{\circ} \mathrm{C}\right)$; and (d) vertical velocity $\left(\mathrm{m} \mathrm{day}^{-1}\right)$. Bold solid curve in (a) denotes the mixed layer depth.

\section{2) Surface COMPOSITES IN THE CYClONE WAKE}

In this and the following subsections, the most robust features are assessed by compositing temperature anomalies (difference between the cyclone and no-cyclone experiments) and their tendency terms along all cyclone tracks. The composite is constructed by averaging all the TC responses over the simulation period on a $12^{\circ}$ crosstrack section centered on the cyclone track at each TC passage point. To investigate the processes at work in the cyclone wake, the composite procedure is performed every day from 10 days before to 30 days after cyclone occurrence; day 0 represents the moment of occurrence of the cyclone inner core. This method provides a synthetic expression of the cyclone wake as a function of time, cross-track distance, and depth. Dispersion is calculated at each point by upper and lower quartiles (cuts off highest and lowest $25 \%$ of data, respectively) of that composited wake evolution. Because of the diversity of cyclones in terms of intensity, motion, location, and development, composited effects are necessarily weaker than the individual response to strong events, but it brings statistical reliability to the analysis.

\section{(i) Cyclone wake evolution}

The composited SST under the cyclone center (Fig. 9a) shows an averaged cooling of $0.8^{\circ} \mathrm{C}$ when all cyclones are considered (winds stronger than $17 \mathrm{~m} \mathrm{~s}^{-1}$; bold solid line) and an averaged cooling of $2.3^{\circ} \mathrm{C}$ for hurricanes (winds stronger than $33 \mathrm{~m} \mathrm{~s}^{-1}$; dashed line). Mixed layer deepening becomes significant a little prior to cyclone occurrence (Fig. 9b) because of wind stress intensification within the cyclone radius. The mixed layer reaches its maximum depth right at cyclone occurrence, ranging from 5- to 15-m deepening, depending on cyclone intensity (Fig. $9 b)$. When the cyclone moves away, the mixed layer is progressively restored to its prestorm value and becomes 


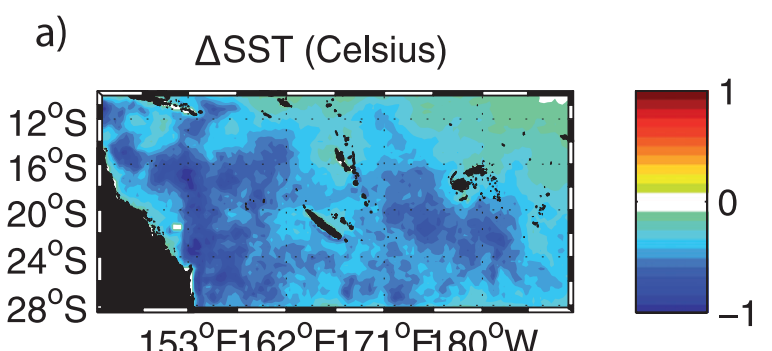

b) $\Delta \mathrm{T}$ at $65 \mathrm{~m}$ (Celsius)

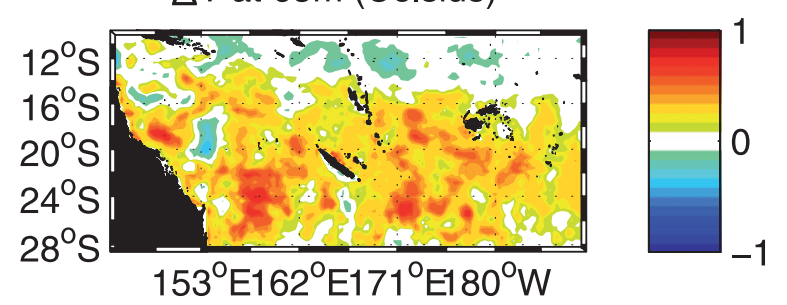

c) $\quad \Delta K z$ at MLD $(\mathrm{m} 2 / \mathrm{s})$
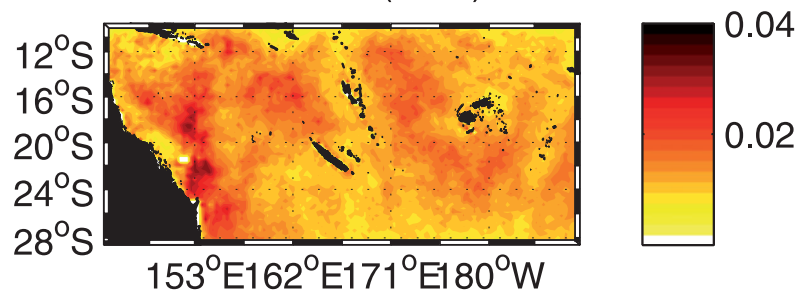

d)

$\triangle$ Wind Stress $(\mathrm{N} / \mathrm{m} 2)$
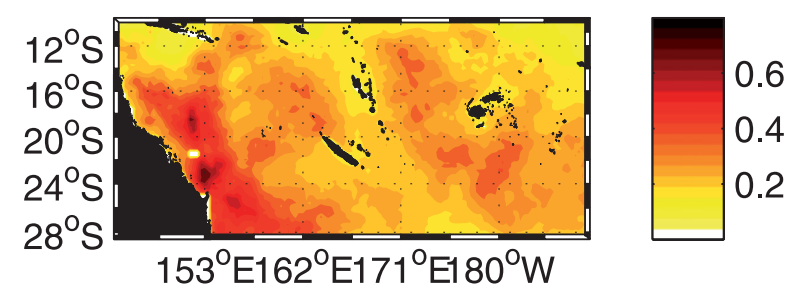

FIG. 8. Composite anomalies of all cyclone tracks (using a $6^{\circ}$ radius) representing the model composited effect of cyclones within a day of their occurrence for (a) the SST $\left({ }^{\circ} \mathrm{C}\right)$; (b) the temperature at $65 \mathrm{~m}\left({ }^{\circ} \mathrm{C}\right)$; (c) the vertical mixing coefficient $\left(\mathrm{m}^{2} \mathrm{~s}^{-1}\right)$; and (d) the wind stress $\left(\mathrm{N} \mathrm{m}^{-2}\right)$.

even shallower 5 days after cyclone occurrence. The maximum cooling is reached in the cyclone wake 2 days after its occurrence (Fig. 9a). After 10 days, cooling is reduced by a factor of 2 , but after 30 days the SST is not totally restored to its prestorm value, presenting a mean anomaly of $-0.2^{\circ} \mathrm{C}$ (Fig. 9a). The dispersion of surface cooling illustrated by the upper and lower quartiles shows the response diversity.

The composited temperature budget in the mixed layer [see Eq. (2)] shows that vertical mixing by entrainment and shear instability is the main process contributing to TC-induced surface cooling (Fig. 9c, black thin solid line). Its effect is mostly apparent during the storm's passage: that is, from 2 days before to $2-3$ days after. This process remains active to a lesser extent until the mixed layer is restored to its prestorm value. The first stage of mixing can be attributed to a wind stirring process, whereas the second stage in the cyclone wake is induced by sheargenerated turbulence associated with inertial currents. Vertical advection appears weak in this budget because its effect on the mixed layer is indirect. Ekman pumping acts in shallowing the mixed layer by uplifting the thermocline (see further in the text). Therefore, its contribution to surface cooling does not appear in the mixed layer budget but contributes to making vertical mixing more efficient. Later in the storm wake, lateral advection (Fig. 9c, dotted line) and atmospheric forcing (Fig. 9c, dashed line) balance shear-driven vertical mixing, reheating the mixed layer. The surface forcing term shows a slight cooling during the cyclone passage and a strong restoring effect in its wake that contributes to the shallowing of the mixed layer (Fig. 9b). Lateral diffusion is negligible during cyclone event and will not be discussed further.

\section{(ii) Cross-track pattern}

A composited cross-track section illustrates the asymmetry of surface cooling during the passage of cyclones (Fig. 10c). The mixed layer deepening appears about 1.5 times larger on the strong side than at the storm center (Fig. 10d). A second maximum of mixed layer deepening is also located on the weak side resulting from relative shallowing at the center due to upwelling (Fig. 10d). The asymmetry of mixed layer deepening is consistent with an increase of vertical diffusivity on the strong side (Fig. 10b). Note that the cross-track structure of TC wind stress (Fig. 10a) is also asymmetric, as expected from the TC translation speed. The increase of vertical mixing on the strong side of the cyclone may thus be either directly induced by wind stirring asymmetry (e.g., Chang and Anthes 1978) or near-inertial oscillations that can be resonant with the wind forcing (e.g., Price et al. 1994). Separating out these effects is beyond the scope of this paper.

The budget analysis confirms that surface cooling is larger on the strong side due to asymmetric vertical mixing (Fig. 10e, black bold and thin solid lines). Lateral advection also contributes to the asymmetry (Fig. 10e, dotted line), in agreement with previous studies (Price 1981; D'Asaro 2003; Huang et al. 2009; Vincent et al. 2012), by cooling the strong side and warming the storm-track center. Surface cooling is greatest 2 days after TC occurrence (Fig. 10f, black bold solid line) and dominated by vertical mixing (Fig. 10f, black thin solid line), which is now stronger right under the TC center. This occurs in response to TC-induced upwelling in the track center, 


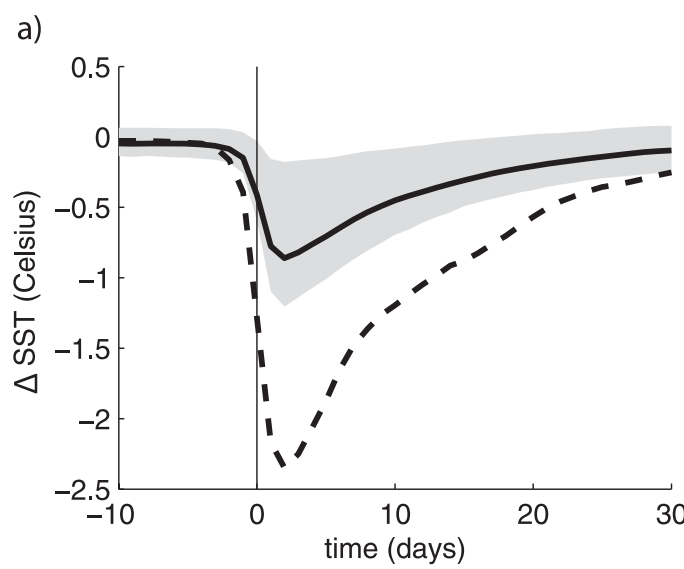

c)

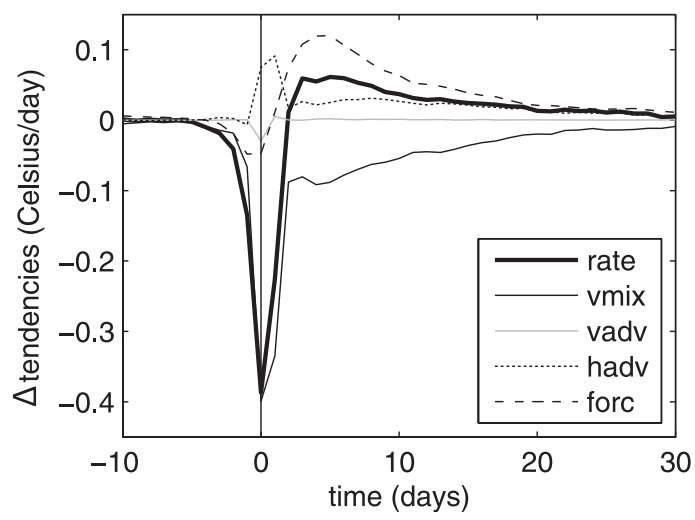

b)

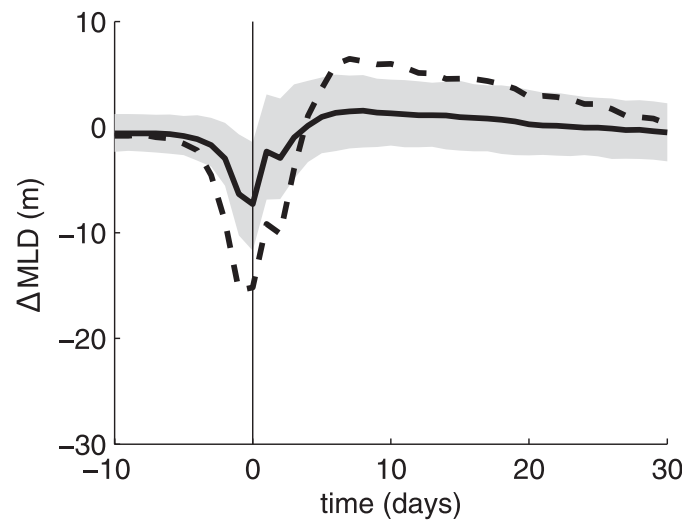

FIG. 9. Model composited cyclone wake anomalies in the storm-track center (over a $0.25^{\circ}$ radius) as a function of time relative to occurrence (marked with a vertical solid line). (a) SST $\left({ }^{\circ} \mathrm{C}\right)$; (b) mixed layer depth (m); and (c) mean temperature tendencies in the mixed layer $\left({ }^{\circ} \mathrm{C}\right.$ day $\left.^{-1}\right)$. For (a),(b), the bold solid curve represents the mean effect of cyclones with wind speed reaching $17 \mathrm{~m} \mathrm{~s}^{-1}$. The upper and lower quartiles of SST and MLD distributions are shaded in gray. The bold dashed curve is the mean effect of hurricanes with wind speed reaching $33 \mathrm{~m} \mathrm{~s}^{-1}$. (c) Tendency terms of surface temperature anomaly budget in the composited cyclone wake; the black bold curve is rate of change, the black thin curve is vertical mixing, the gray curve is vertical advection, the dotted curve is horizontal advection, and the dashed curve is surface forcing. itself occurring between days 0 and 2, depending on the translation speed. As suggested in the previous section, upwelling helps the mixing process by uplifting cold water near the mixed layer base. Yet, the SST response is still asymmetric because the increased mixing at the center is largely balanced there by lateral advection. The latter also exerts cooling in the strong side (Fig. 10f, dotted line).

\section{3) SubSurface WATERS}

\section{(i) Cyclone wake evolution}

The evolution of heat budget at depth in the composited cyclone wake (in the wake center) is presented in Fig. 11 (see also the accumulated tendencies in Fig. 13). A few days before cyclone occurrence, vertical mixing at the mixed layer base increases, forced by the outer cyclone winds. This process moves heat from the mixed layer to the upper thermocline (Fig. 11b): that is, it warms subsurface waters. During the cyclone passage, Ekman pumping produces strong cooling by vertical advection of temperature (Fig. 11c), which overcomes the mixing-induced warming below the mixed layer (Figs. 11a,b) and cools the water column down to $1000 \mathrm{~m}$ (not shown). Such a deep impact of Ekman pumping is also noted in Scoccimaro et al. (2011). After 2-3 days, these processes stop operating and slight oscillations are apparent because of the imperfectly smoothed NIOs. Interestingly, once the strong cooling by combined vertical advection and mixing has stopped, lateral advection becomes an active player and somewhat compensates for the subsurface cooling between the mixed layer base and $200 \mathrm{~m}$. This lasts for a period of about 10 days after the cyclone passage (Figs. 11a-d). However, previous cooling by vertical advection is so intense that it persists long after cyclone occurrence (see Fig. 13a).

\section{(ii) Cross-track pattern}

Figure 12 presents a cross section of the composited heat budget, integrated between days -2 and +5 . It shows that vertical mixing (Fig. 12b) tends to warm the upper thermocline well off the track center, especially on the strong side (Figs. 12a,b). Yet, within $200 \mathrm{~km}$ of the center, the warming trend due to mixing is overwhelmed by cooling due to Ekman pumping that has a maximum effect near the mixed layer base (Fig. 12c). The vertical advection of temperature thus has the dual effect of cooling the water column and increasing the 
a)

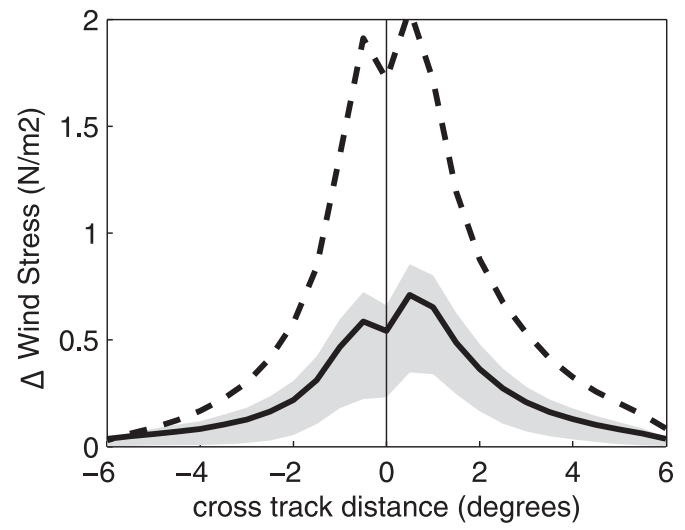

c)

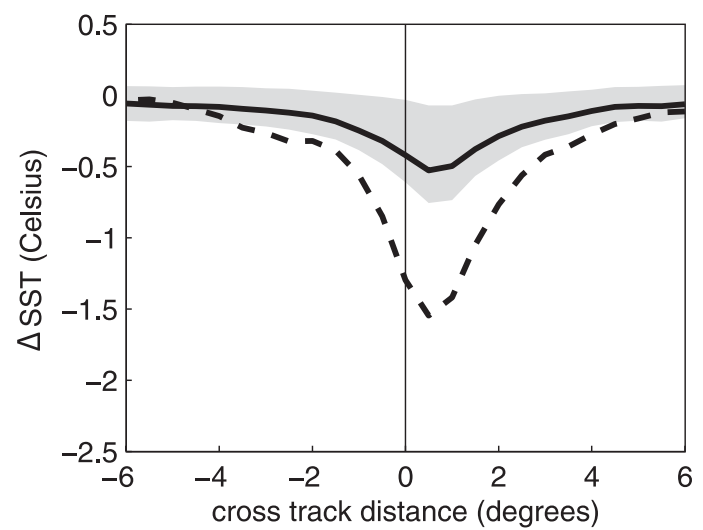

e)

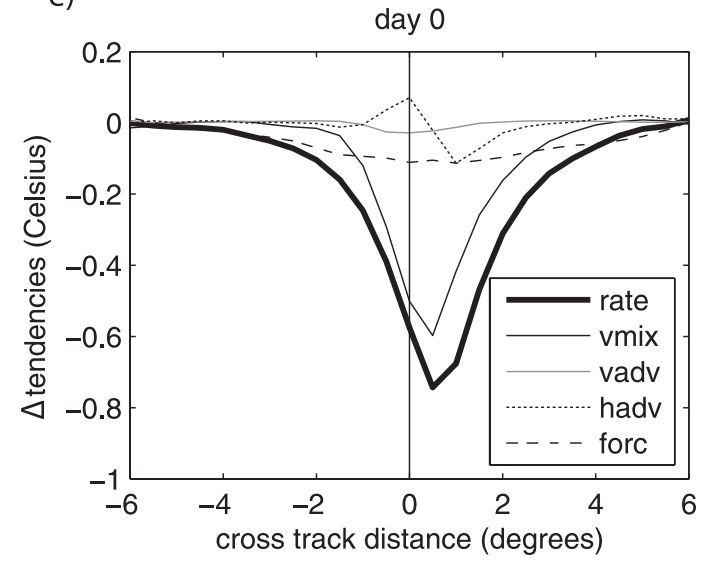

b)

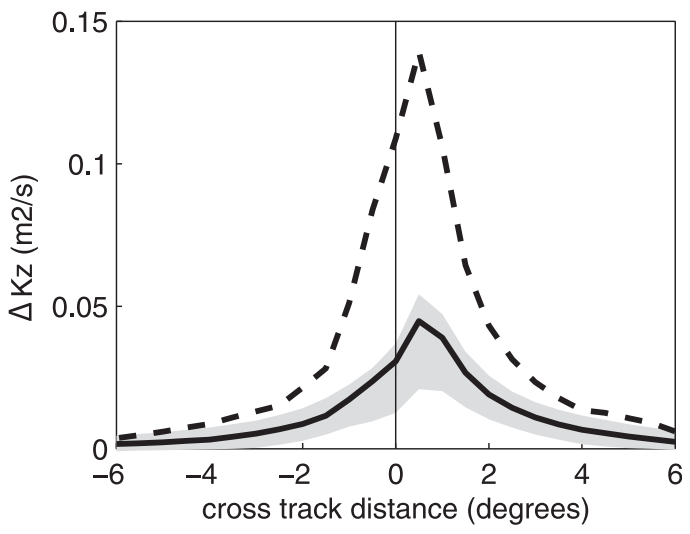

d)

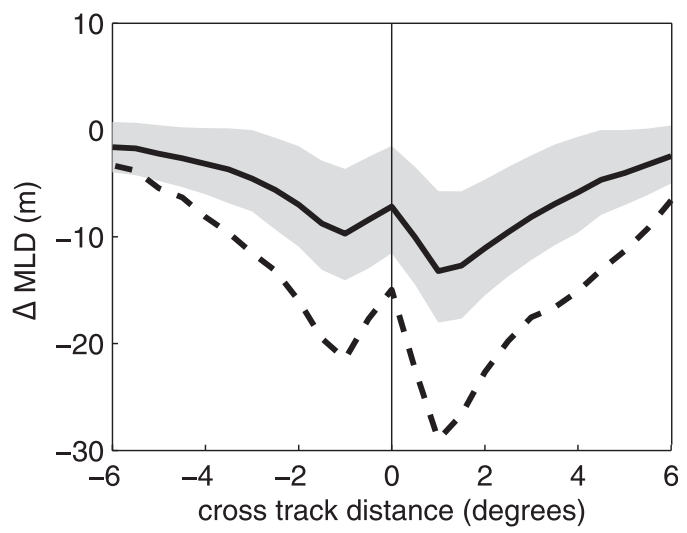

f)

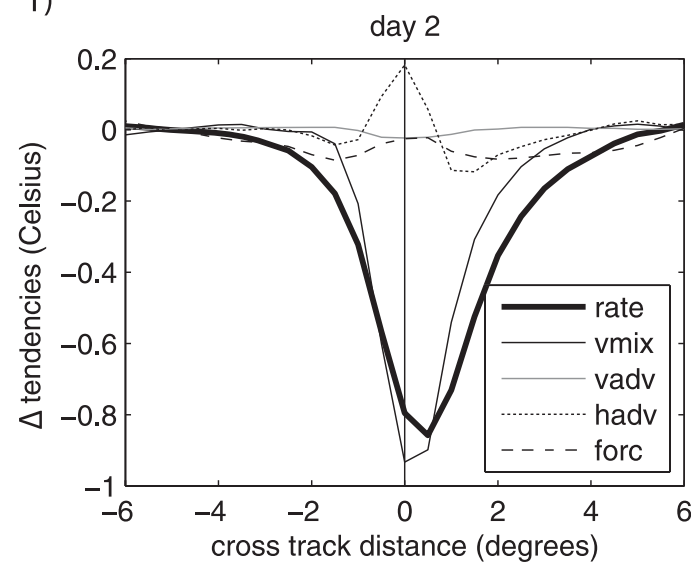

FIG. 10. Model composited anomalies at the time of TC center crossing as a function of cross-track distance to the cyclone center, where negative (positive) distances denote the cyclone's weak (strong) side. Shown are (a) the wind stress $\left(\mathrm{N} \mathrm{m}^{-2}\right)$; (b) the vertical mixing coefficient at the mixed layer base $\left(\mathrm{m}^{2} \mathrm{~s}^{-1}\right)$; (c) SST $\left({ }^{\circ} \mathrm{C}\right)$; and (d) mixed layer depth $(\mathrm{m})$. The bold solid curve is the mean effect of cyclones with wind speed reaching $17 \mathrm{~m} \mathrm{~s}^{-1}$ (upper and lower quartiles are shaded in gray as in Fig. 9) and the bold dashed curve is the mean effect of hurricanes with wind speed reaching $33 \mathrm{~m} \mathrm{~s}^{-1}$. (bottom) Temperature budget terms in the mixed layer integrated (e) between days -2 and $0\left({ }^{\circ} \mathrm{C} \mathrm{day}^{-1}\right)$ and (f) between days -2 and 2 . The black bold curve is rate of change, the black thin curve is vertical mixing, the gray curve is vertical advection, the dotted curve is horizontal advection, and the dashed curve is surface forcing. 

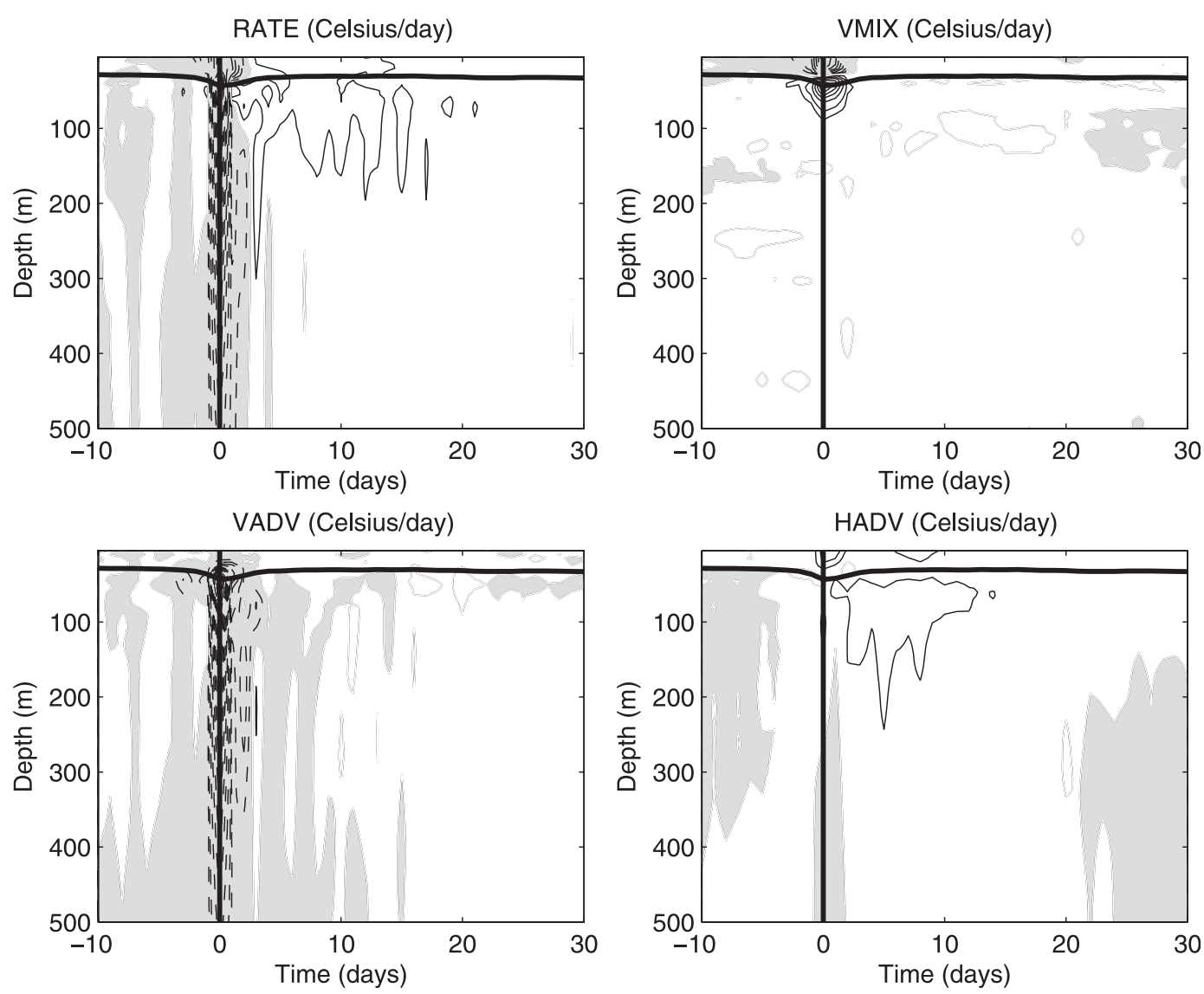

FIG. 11. Model composited anomalies of temperature tendencies $\left({ }^{\circ} \mathrm{C} \mathrm{day}{ }^{-1}\right)$ in the cyclone wake over the first $500 \mathrm{~m}$ in the storm-track center (averaged over $0.25^{\circ}$ radius) as a function of time relative to occurrence. Shown are (a) rate of change, (b) vertical mixing, (c) vertical advection, and (d) horizontal advection. Dashed contours and gray areas are for negative values; solid contours and white areas are for positive values. The contour interval is $0.05^{\circ} \mathrm{C}_{\text {day }}{ }^{-1}$ with additional 0.025 positive and negative contours. The bold solid line is the mixed layer.

temperature gradient at the mixed layer base, as previously noted. In our model, because some cyclones reach the Australian coastline or the open boundaries, Ekman pumping in the composite storm center is not totally balanced by that of downwelling on the sides. More importantly, vertical advection is a nonlinear effect of Ekman pumping and has residual value in an open system that can exchange energy through its boundaries (the cyclone's oceanic response is embedded within a background flow that can transport anomalies out of the TC footprint area). As a result, a weaker warming by advection occurs on the sides of the storm track compared to cooling in the center. It is mainly vertical mixing, not advection, that provides subsurface warming on the sides, particularly on the strong side of the storm track (Figs. 12a,b).

A synthetic picture of the integrated effect of the cyclone passage between days -2 and 5 averaged over the whole cross-track composite is given in Fig. 12e. The vertical distribution of the processes can be separated into roughly three layers: the surface layer $(0-30 \mathrm{~m})$, representative of SST variations under the composite cyclone; a subsurface layer $(30-150 \mathrm{~m})$ in the upper thermocline where vertical mixing and advection are the main players; and a deep layer (below $150 \mathrm{~m}$ ) where vertical mixing shows poor activity. In the surface layer, vertical mixing controls most of the cooling under the cyclone passage, which results in an averaged cooling of $-0.2^{\circ} \mathrm{C}$ over the cross track. In the subsurface layer, warming is due to vertical mixing and lateral advection but vertical advection has a cooling effect. Therefore, only a fifth of the heat exchanged between the surface and subsurface layers results in subsurface warming. This suggests that estimates of subsurface warming based only on equivalent surface cooling (e.g., in Emanuel 2001) may be overestimated by $80 \%$. The balance between advection and mixing results in a slight subsurface warming of $0.05^{\circ} \mathrm{C}$ in the cross-track composite. In the deep layer (below $150 \mathrm{~m}$ ), vertical advection has a strong cooling effect partly balanced by lateral advection. In conclusion, the mean cyclone 
a)

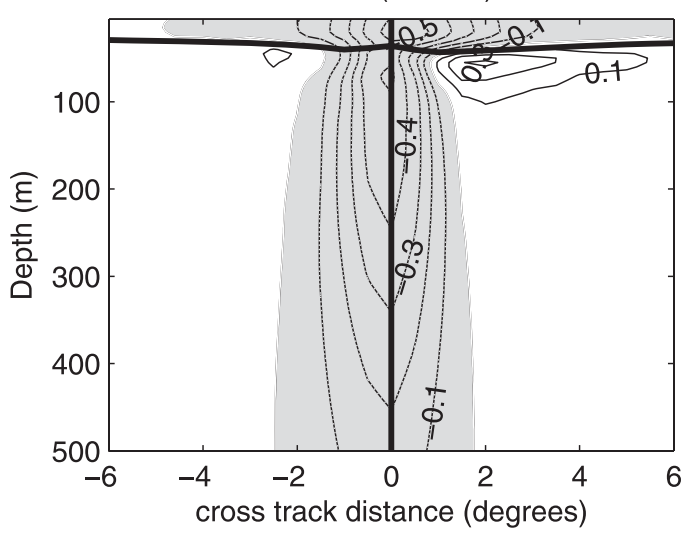

c)

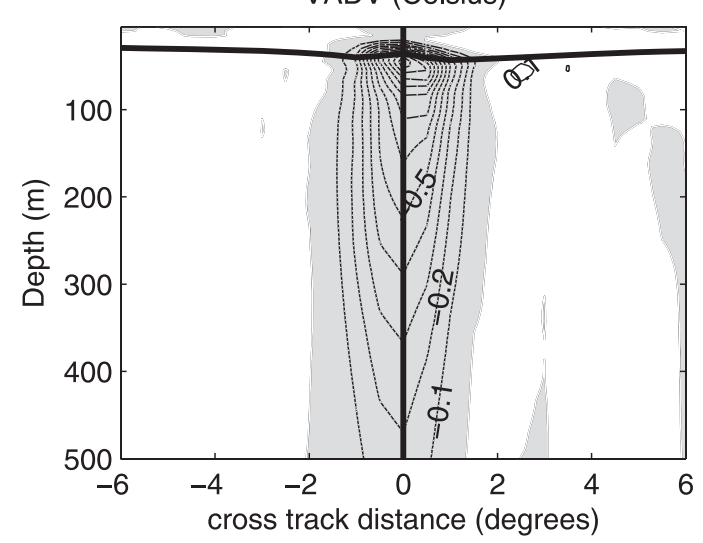

e)

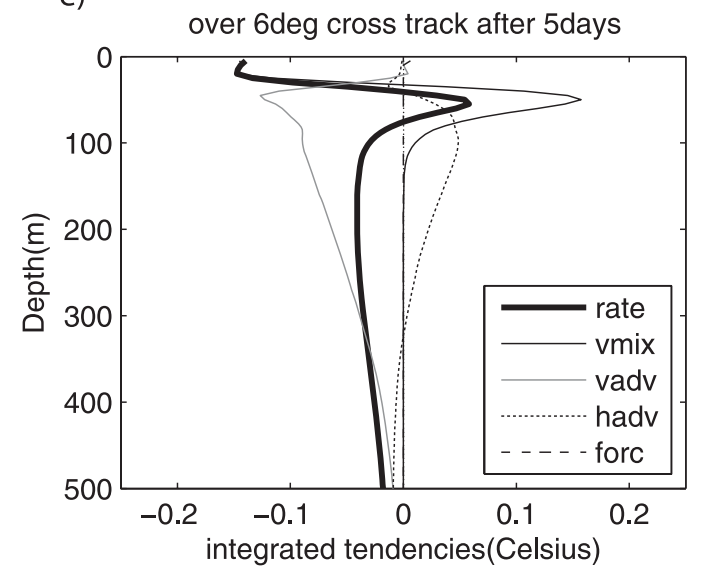

b)

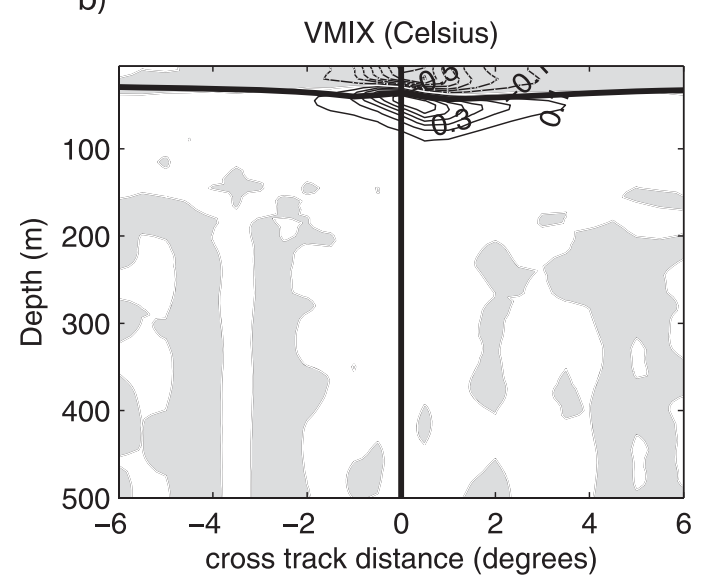

d)

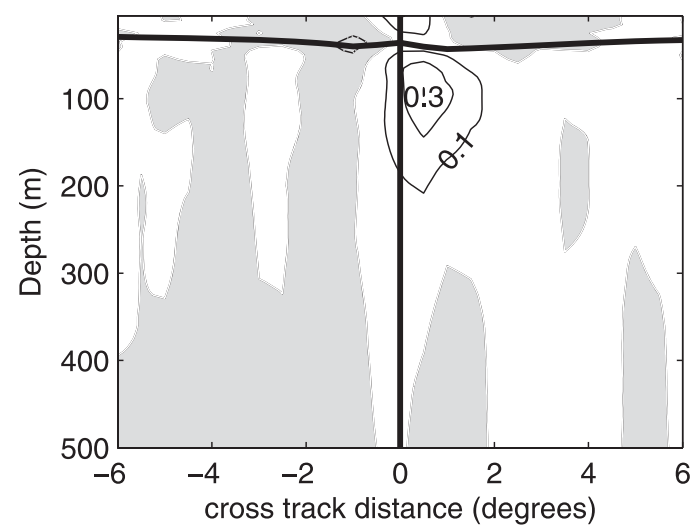

f)

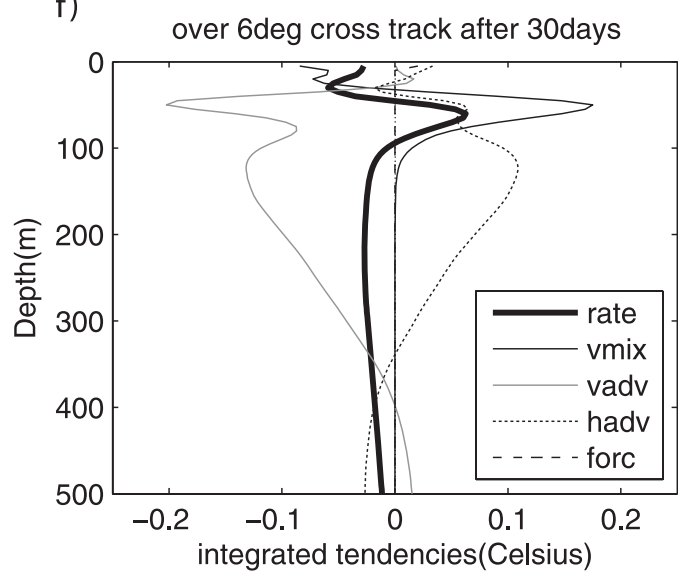

FIG. 12. Model composited anomalies of temperature tendencies $\left({ }^{\circ} \mathrm{C}\right)$ integrated between days -2 and +5 on a cross-track section: (a) rate of change; (b) vertical mixing; (c) vertical advection; and (d) horizontal advection. Dotted contours and gray areas are for negative values; solid contours and white areas are for positive values. The contour interval is $0.1^{\circ} \mathrm{C}$. The bold solid curve is the mixed layer depth and the vertical solid line is the track center. (e) Section-averaged composite anomalies integrated between days -2 and +5 . (f) As in (e), but integrated between days -2 and 30 . The black bold curve is the rate of change, the black thin curve is vertical mixing, the gray curve is vertical advection, the dotted curve is horizontal advection, and the dashed curve is surface forcing. 

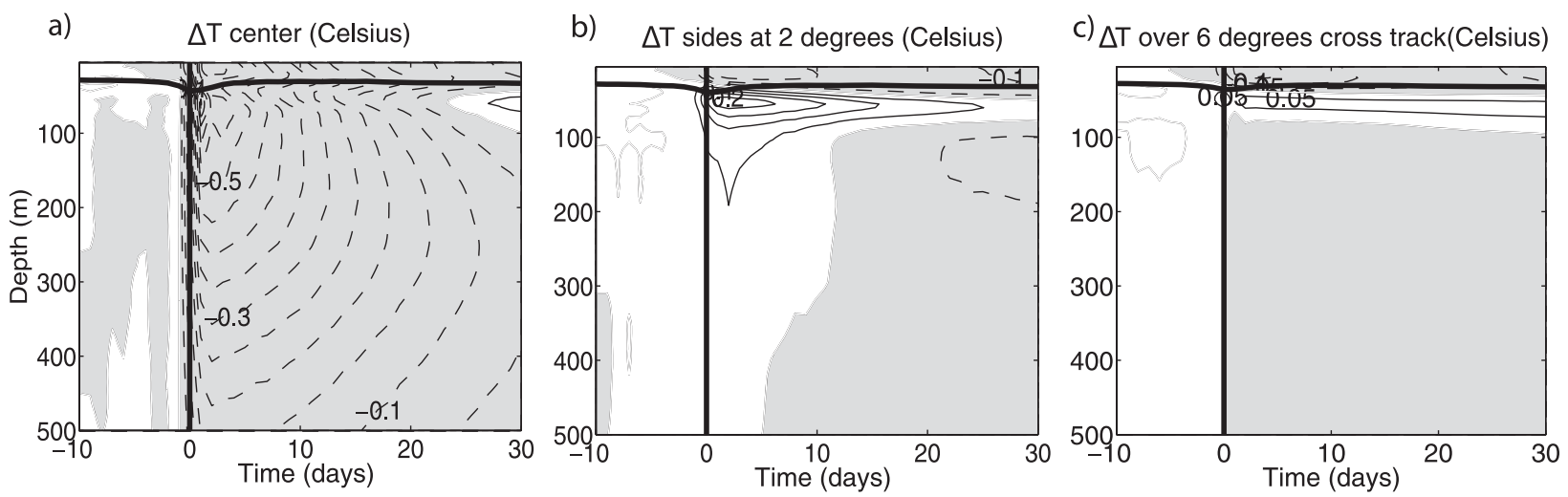

FIG. 13. Model composited anomalies of temperature $\left({ }^{\circ} \mathrm{C}\right)$ as a function of time relative to cyclone occurrence (a) at the track center, $(\mathrm{b})$ $2^{\circ}$ off the center on both sides, and (c) averaged over a $6^{\circ}$ radius cross-track section (see Fig. 12). Dashed contours and gray areas are for negative values; solid contours and white areas are for positive values. Contour interval is $0.05^{\circ} \mathrm{C}$. The bold solid curve is the mixed layer depth and vertical solid line is the cyclone passage time.

effect is to cool the ocean surface, moderately warm the subsurface, and moderately cool the deep ocean.

\section{4) INTEGRATED EFFECT IN THE CYCLONE WAKE}

We now assess the time-integrated effect of all these processes on the temperature changes between days -2 and 30 in order to highlight the persistent temperature changes due to cyclones. Except for the surface layer, the mean aspect of temperature tendencies averaged over the cross-track section is very similar to the one presented from day -2 to day 5 in the previous section (Figs. 12e,f), emphasizing the persistence of effects produced during the cyclone passage below the mixed layer. In the surface layer, once cooling has occurred, surface heat fluxes and lateral advection progressively tend to restore the background temperature, resulting in weaker cooling in the 30-day-long cyclone wake (cf. Figs. 12e,f). In the subsurface and deep layers, the balance of processes described in the previous section remains valid in the longer term but with more prominent advection, particularly lateral advection. After the forced stage and up to four inertial periods, lateral advection is mostly driven by near-inertial motions (as shown in Fig. 7b). After a week and even more after a month, the effect of near-inertial currents begins to subside, whereas lateral advection remains high because of background currents that redistribute anomalies away from TC wakes.

Finally, Fig. 13 gives a mean picture of temperature evolution in the cyclone wake. The main effects occur in the storm-track center (Fig. 13a), except for the subsurface layer, which is significantly warmed on the sides (Fig. 13b). Therefore, the generic TC effect, 30 days after its passage, is qualitatively similar to its effect during occurrence: cooling in the surface and deep layers and warming in the subsurface. With particular reference to vertical mixing and vertical advection, the processes involved at the time of the cyclone passage (from day -2 to day 2), dominate the subsequent evolution of temperature. The only major difference appearing after the cyclone passage is associated with lateral advection, which increases with time: its role being to redistribute cyclone-induced anomalies across the region. Lateral advection in particular explains the smoothing with time of the differential response appearing between the storm-track center and its sides (cf. Figs. 13a-c).

\section{c. TC impacts on the ocean climate}

The remaining question - the climatological impact of cyclones - is a primary motivation for this study and will now be addressed. We address the problem by analyzing differences between the cyclone and no-cyclone experiment climatologies; for interpretation, we rely on the process study of the previous sections.

\section{1) Surface TEMPERATURE}

The mean annual SST difference between the cyclone and no-cyclone experiments is presented in Fig. 14a. SST anomalies are weak but clearly organized in a regional pattern with cooling areas north of $15^{\circ} \mathrm{S}$ and warming patches south of $15^{\circ} \mathrm{S}$. Decomposing these SST patterns into the summer cyclonic season (Fig. 14b) and winter cyclone-free season (Fig. 14c) reveals interesting features. During the summer season, climatological SST anomalies are negative $\left(\sim-0.1^{\circ} \mathrm{C}\right)$ and in agreement with TC-induced surface cooling (see Fig. 8a). In contrast, winter climatological SST anomalies show a tendency toward positive values south of $15^{\circ} \mathrm{S}$. This suggests that, during winter, some of the heat previously stored under the mixed layer reemerges in the surface layer. Winter surface heat fluxes south of $15^{\circ} \mathrm{S}$ act to cool down 
a)

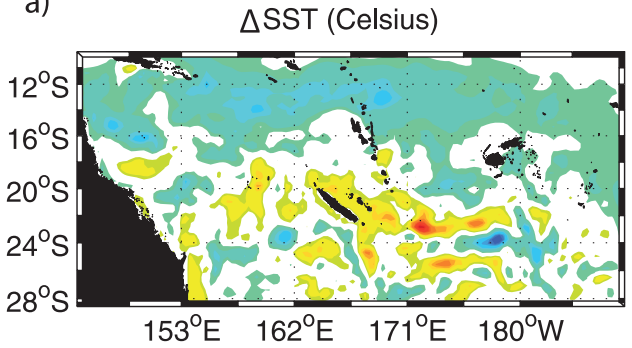

b)

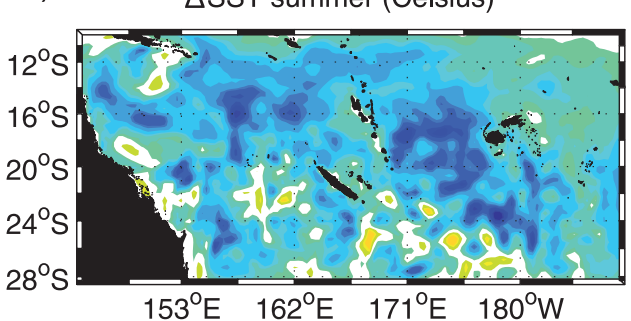

c)
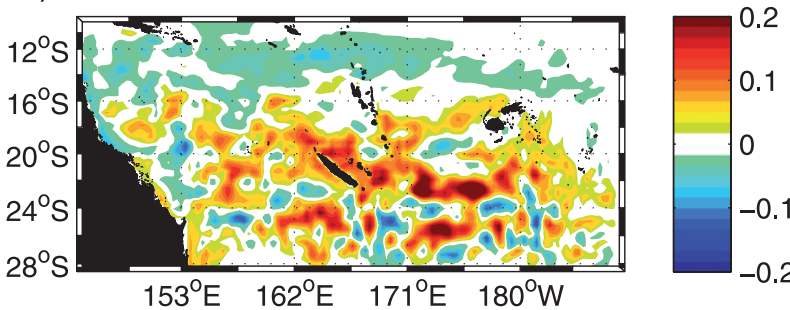

FIG. 14. Model-mean SST anomalies $\left({ }^{\circ} \mathrm{C}\right)$ for (a) the whole period 1979-2003; (b) summer months (JFM) only; and (c) winter months [July-September (JAS)] only.

SST and deepen the mixed layer through a negative buoyancy flux at the air-sea interface. As a result, winter entrainment transports back to the surface warm anomalies stored in the subsurface during summer. This reemergence process is in agreement with the observations of Jansen et al. (2010). North of $15^{\circ} \mathrm{S}$, summer TCinduced mixing is weak because of the deep warm pool thermocline that isolates cool subsurface waters from surface turbulence; there is little storage of warm anomalies in this case. Therefore, when adding the two seasons to evaluate the surface climatological effect of cyclones (Fig. 14a), the overall tendency is weak and differs south and north of $15^{\circ} \mathrm{S}$.

\section{2) Vertical STRUCTURE}

We now turn to the vertical distribution of climatological temperature anomalies. The close similarity between the mean climatological anomaly profile (Fig. 15d, black bold curve) and the equivalent profile of integrated temperature changes in the composited cyclone wake (Fig. 12f, black bold curve) demonstrates that climatological effects can be understood from the study of composited cyclone wakes. Figure $15 \mathrm{c}$ shows a zonally averaged warm anomaly of up to $0.12^{\circ} \mathrm{C}$ in the subsurface layer, reaching down to $300 \mathrm{~m}$ in the southern region. This pattern is well correlated with vertical diffusivity anomalies (Fig. 15c, black contours) and wind stress anomalies (Fig. 15a) as expected from the TCinduced mixing process. A slight SST cooling in both surface and subsurface layers is apparent in the northern region as previously noticed and can be attributed to the warm pool deep thermocline (Fig. 15c, blue lines) that limits vertical mixing (a shallow process) more than it does vertical advection. This allows for neither important subsurface heat storage during the cyclonic season (Fig. $8 b)$ nor reemergence of heat content in winter (Fig. 14c).

In the deep layer, the pattern is dominated by a cold anomaly of up to $-0.08^{\circ} \mathrm{C}$ reaching down to $450 \mathrm{~m}$ with a maximum between $16^{\circ}$ and $20^{\circ} \mathrm{S}$. Deep warm anomalies surround this central pattern. This can be explained by the climatological distribution of TC-induced Ekman pumping. Vertical advection in TC wakes is characterized by strong upwelling in the TC core and weaker but more widely spread downwelling around the track. At climatological scale, the juxtaposition of TC tracks would have the apparent effect of moving the downwelling signal of each TC footprint toward the edges of TC distribution while maintaining upwelling in the center. Figure 15b displays the mean TC-induced Ekman $\operatorname{pumping}^{4}\left[w_{E}=\operatorname{curl}\left(\tau / \rho_{0} f\right)=\operatorname{curl}(\tau) / \rho_{0} f+\beta \tau_{x} / \rho_{0} f^{2}\right.$, where $\tau_{x}$ is the zonal component of wind stress $\tau, \rho_{0}$ is the density of seawater, and $\beta$ is the gradient of Coriolis frequency $f$ ]. It shows a very good correlation between latitudinal patterns of Ekman pumping and subsurface temperature anomalies (the correlation coefficient is 0.86 at $200 \mathrm{~m}$ ). The minimum deep temperature anomaly around $18^{\circ} \mathrm{S}$ is well collocated with the maximum Ekman pumping. North of $15^{\circ} \mathrm{S}$, where vertical mixing is weaker, Ekman pumping can even affect the subsurface layer. On the other hand, Ekman downwelling impacts the meridional limits of TC distribution (north of $10^{\circ} \mathrm{S}$ and south of $24^{\circ} \mathrm{S}$ ) and is collocated with deep warm anomalies. The asymmetric effect of $\beta$ in $w_{E}$ is also of interest (cf. solid and dashed lines in Fig. 15b), enhancing the southern downwelling signal. Note that total vertical advection resulting from extreme Ekman pumping in TC cores is not totally balanced by warming associated with downwelling on the sides. Integrated over TC footprints,

\footnotetext{
${ }^{4}$ The effect of underlying currents in modulating Ekman pumping (see Jaimes and Shay 2009, and references therein) results from interaction between wind stress and relative vorticity. This effect is not included here but should be investigated in further studies using higher-resolution simulations.
} 


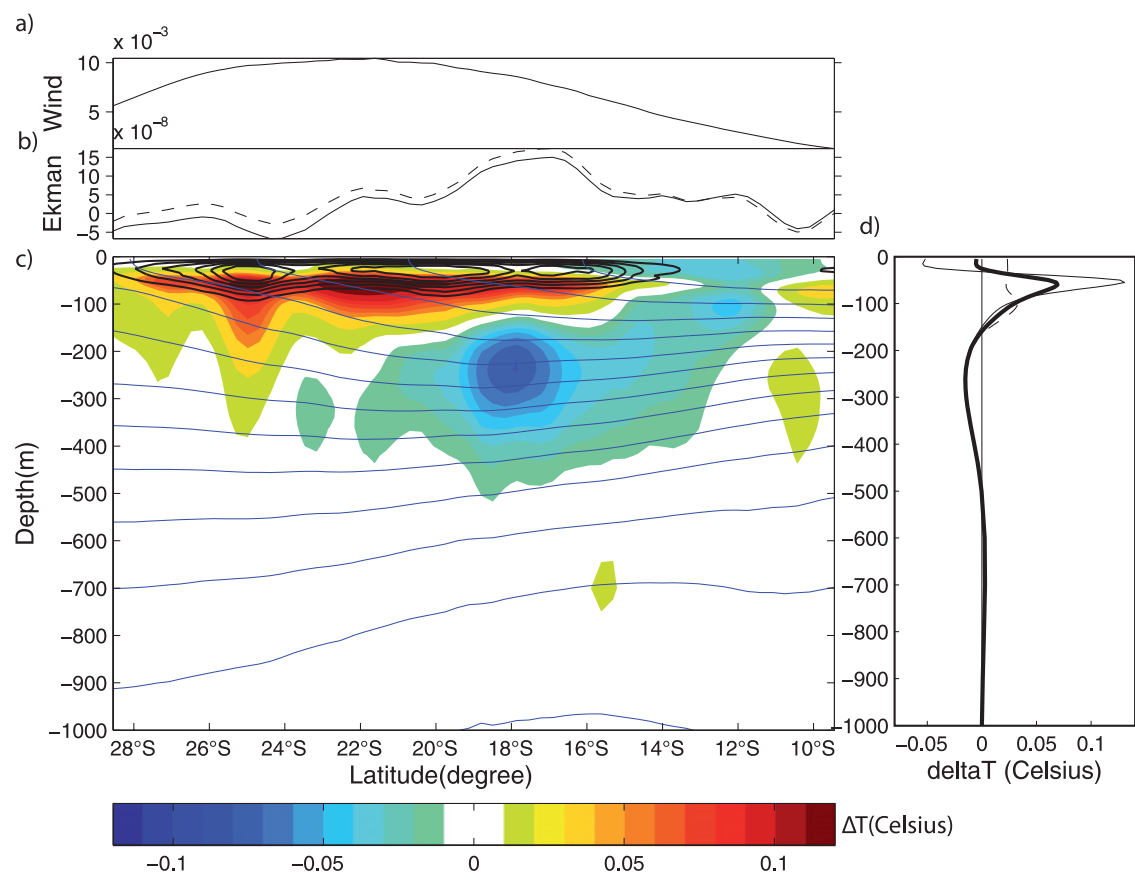

FIG. 15. Model zonal averages of various climatological field anomalies: (a) wind stress $\tau$ $\left(\mathrm{N} \mathrm{m}^{-2}\right)$; (b) Ekman pumping $w_{E}=\operatorname{curl}(\tau / \rho f)=\operatorname{curl}(\tau) / \rho f+\beta \tau_{x} / \rho f^{2}$, where $\tau_{x}$ is the zonal component of wind stress $\tau, \rho$ is the density of seawater, and $\beta$ is the gradient of Coriolis frequency $f$ (solid line) and the dashed line presents only the first component of Ekman pumping (i.e., Ekman pumping assuming no beta effect); and $(\mathrm{c})$ temperature section $\left({ }^{\circ} \mathrm{C}\right)$, where black contours represent vertical diffusivities ranging from 5 to $20 \mathrm{~cm}^{2} \mathrm{~s}^{-1}$ with a contour interval of $3 \mathrm{~cm}^{2} \mathrm{~s}^{-1}$ and blue curves show the stratification of the control run (isotherms with $2^{\circ} \mathrm{C}$ interval); (d) space- and time-averaged temperature profile for the annual mean (bold black curve), JFM months (thin solid curve), and JAS months (dashed curve).

total Ekman pumping would cancel if, according to the Kelvin-Stokes theorem, wind anomalies were zero along all footprint boundaries. However, this is not the case here because some cyclones reach the Australian coastline or the model open boundaries. Lateral advection of heat anomalies by the regional circulation and Rossby wave propagation are essentially zonal redistribution processes (Couvelard et al. 2008), but the presence of numerous islands and especially the Australian continent are responsible for meridional redistribution that must also be accounted for in the latitudinal anomaly pattern of Fig. 15.

The vertical distribution of climatological temperature anomalies is finally explained by the temperature box budget presented in Table 2 . The rate of change term can be used as a measure of statistical reliability of our climatological budget over the $25 \mathrm{yr}$ of seasonal TC forcing. It is on the order of $10^{11} \mathrm{~W}$; that is, only $1 \%-10 \%$ of

TABLE 2. Box budget of climatological temperature anomalies between the cyclone and no-cyclone simulations. The budget is horizontally integrated over the entire domain and vertically integrated over three layers: the surface layer (0-30 m), the subsurface layer (30$150 \mathrm{~m}$ ), and the deep layer (150 $\mathrm{m}$ to ocean bottom). The vertically integrated budget over the whole depth is also presented for the annual mean, the summer period (November-April) and the winter period (May-October). The term RATE is the rate of change of temperature anomalies (also a proxy for statistical error); HMIX is lateral diffusion; FORC is surface forcing, VMIX is vertical mixing; VADV is vertical advection; HADV is lateral advection; and ADV is total advection VADV+HADV (which equals the transport through the boxes).

\begin{tabular}{|c|c|c|c|c|c|c|c|}
\hline Units: $10^{13} \mathrm{~W}$ & RATE & HMIX & FORC & VMIX & VADV & HADV & $\mathrm{ADV}$ \\
\hline $0-30 \mathrm{~m}$ & -0.01 & 0.00 & 0.29 & -0.63 & 0.08 & 0.25 & 0.33 \\
\hline $30-150 \mathrm{~m}$ & 0.04 & -0.05 & 0.00 & 0.62 & -1.88 & 1.35 & -0.53 \\
\hline $150 \mathrm{~m}$-bottom & 0.01 & -0.03 & 0.00 & 0.01 & -0.71 & 0.74 & 0.03 \\
\hline Total depth climatology & 0.04 & -0.08 & 0.29 & 0.00 & -2.51 & 2.34 & -0.17 \\
\hline Total depth summer & 0.65 & -0.10 & 1.48 & 0.00 & -5.68 & 4.95 & -0.73 \\
\hline Total depth winter & -0.56 & -0.06 & -0.91 & 0.00 & 0.66 & -0.26 & 0.40 \\
\hline
\end{tabular}



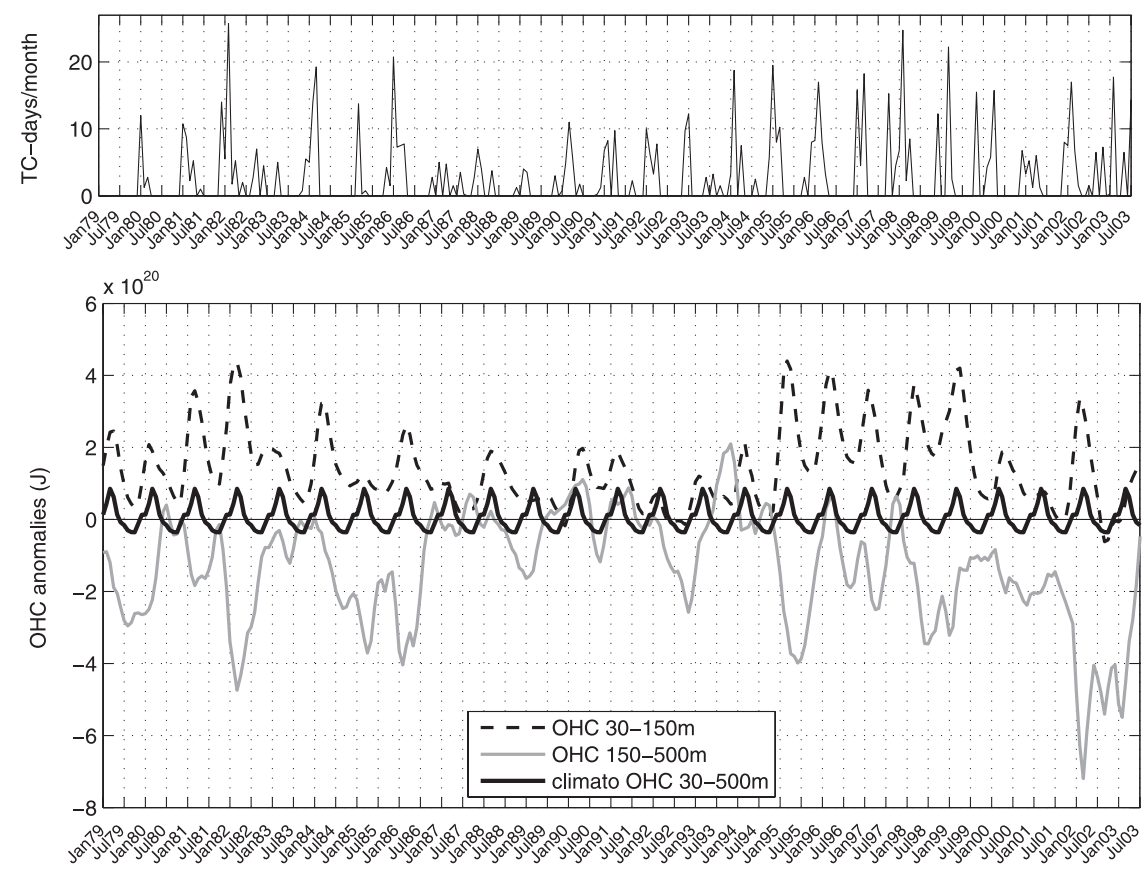

FIG. 16. Time series of (a) the number of simulated cyclone days per month (the first six months of 1979 are not represented) and (b) the integrated OHC anomaly (J) over 30-150-m depths (dashed line) and 150-500-m depths (gray solid line). The climatological heat content anomaly of the $30-500-\mathrm{m}$ layer (black solid line) is repeated each year as a reference.

the other terms. The balance of these terms appears similar here to the one presented for the composited cyclone wake. It confirms that the only cooling process at work below 30-m depth is vertical advection. Integrated over the whole water column, vertical and horizontal contributions to advection nearly balance and the remaining part equals lateral boundary fluxes. The result is a net heat input through the ocean surface (due to surface cooling by TC vertical mixing) compensated by heat transport through open boundaries (mostly by advection but with a weak contribution from turbulent diffusion).

Figure $15 \mathrm{~d}$ presents annual, summer, and winter regional averages of temperature anomaly profiles and Table 2 (last three lines) the associated tendencies over the whole depth. It confirms that part of the subsurface warm anomaly stored during summer is fed back to the mixed layer (and to the atmosphere) during winter. Winter mixed layer deepening is clearly responsible for the smoothing of the summer temperature anomaly profile between 0 and $100 \mathrm{~m}$. Heat anomaly ${ }^{5}$ entering

\footnotetext{
${ }^{5}$ Heat anomaly is calculated by integrating the surface heat flux over the computational domain and averaging the result over the season (November-April for cyclonic season and May-October for winter).
}

the ocean surface during the cyclonic season amounts to $\sim 0.015 \mathrm{PW}$, and heat anomaly released back to the atmosphere during winter amounts to $\sim 0.009 \mathrm{PW}$. Therefore, in a climatological sense, only $\sim 40 \%$ of the heat input by cyclones in summer permanently modifies the ocean thermocline. The remaining regional anomaly is weak with a maximum of $\sim 0.07^{\circ} \mathrm{C}$ in the subsurface layer, which represents less than $10 \%$ of the seasonal variations. The deeper cold anomaly is also reduced during winter by transport through the open boundaries (advection in Table 2) and is only $70 \%$ of TC-induced cooling.

\section{3) INTERANNUAL VARIABILITY}

Time series of ocean heat content (OHC) anomalies induced by TCs [Fig. 16; OHC $=\rho_{0} C_{p} \int_{h} \int_{y} \int_{x}$ ( $\left.T_{\text {CYCLONE }}-T_{\text {NOCYCLONE }}\right) \partial x \partial y \partial z$, where $h$ is the depth of selected layer] confirm that the heat budget at depth is seasonally affected by TCs but with marked interannual variations (Fig. 16b, dashed and gray lines). In the 30-150-m subsurface layer where wind-driven mixing dominates, heat input is a robust feature of the summer period (Fig. 16b, dashed line). Interannual variability is equally strong in this layer and appears to match the variability of TC activity with a correlation coefficient of 0.8 (Fig. 16a). In the 150-500-m layer, the variability of OHC anomalies (Fig. 16b, gray line) has a lower correlation with TC activity of 0.5 (and 0.6 with 30-150-m OHC 
anomalies). Therefore, this deep interannual signal is driven by seasonal surface forcing during the cyclonic season and nonseasonal variability of the regional subsurface circulation at other times. These results confirm that a significant portion of heat input under the mixed layer is either systematically lost to the atmosphere at seasonal time scale (winter entrainment) or transported by the flow outside the cyclogenesis region with interannual variability. In the long term $(25 \mathrm{yr})$, there is no sign of heat accumulation due to cyclonic forcing.

\section{Conclusions and discussion}

In this study, we have detailed for the first time the long-term, three-dimensional ocean temperature response to cyclone forcing in the southwest Pacific. To that end, we used the surface wind stress of a $1 / 3^{\circ} \mathrm{WRF}$ regional atmospheric simulation over the period 1979 2003 (Jourdain et al. 2011). This simulation contains realistic TC structure and distribution, albeit with fewer extreme cyclones than observed. However, such intense cyclones are rare in the southwest Pacific and are shown to have no statistical effect on the ocean response. The ocean impact of simulated TCs is assessed through the use of a regional $1 / 3^{\circ}$ ROMS ocean model configuration. The model response to TCs is computed using differences between twin experiments: one with cyclone forcing (the cyclone experiment) and the other with cyclonefree forcing where extreme cyclone wind speeds are clipped (the no-cyclone experiment). The surface expression of TC-induced ocean wake is first compared with satellite data and shows a very good match. This successful validation and the model's capability to properly reproduce phenomena such as near-inertial oscillations leads us to believe that the model response is adequate to study the processes at work in nature. To evaluate the oceanic response to TC wind forcing, we then produce composites of all TC wakes to form a generic cyclone wake. The respective contribution of each process in producing temperature anomalies in the composited cyclone wake is assessed using a $3 \mathrm{D}$ temperature heat budget. With the processes uncovered, we explore the climatological impact of TCs in the southwest Pacific.

The surface cooling bias on the strong side (left side in the Southern Hemisphere), observed in various events, is shown in our simulations to be robust and associated with various processes. During the cyclone passage, a cooling bias is driven by asymmetric vertical mixing: that is, wind stirring and shear-driven mixing from nearinertial currents. SST asymmetry is further reinforced by horizontal advection, cooling the strong side and warming the track center. Surface cooling is maximum 2 days after the cyclone passage and mostly driven by vertical mixing as suggested in previous studies. However, during the forced stage, vertical mixing acts also as a relay to another key process: TC-induced upwelling by Ekman pumping. As suggested by Price (1981), this relay process is most efficient at the storm-track center where upwelling is produced. The cooling bias is then shown to rely on asymmetric horizontal advection, as previously suggested from case studies (Price 1981; D'Asaro 2003; Huang et al. 2009). In the cyclone wake (i.e., after the passage of the cyclone), shear-driven mixing remains the only mixing process at work. Vertical advection has a lesser impact, and surface temperature is restored back to prestorm values by surface fluxes and lateral advection. Yet, restoration is never fully achieved during the cyclone season and leaves a mean residual anomaly of $-0.2^{\circ} \mathrm{C}$.

The subsurface layer experiences quite a different balance, with warming on both sides of the track and cooling at the track center during the cyclone passage. At the track center, a strong cooling that can reach down to $1000 \mathrm{~m}$ is driven by vertical advection from Ekman pumping within the TC core. Vertical advection then competes and overwhelms the warm anomaly set at depth by vertical mixing. On the sides, heat input by vertical mixing dominates, thus creating two warm lobes across the track center down to $100 \mathrm{~m}$, with a larger effect on the strong side. Long after the cyclone passage, horizontal advection is also shown to produce warming at the track center, which eventually cancels out the initial cooling because of vertical advection. In the deep layer, below $\sim 150 \mathrm{~m}$, there is a weak but widespread cold anomaly resulting from a balance between cooling by vertical advection and warming by lateral advection. On the sides, the role of advection is reversed because of horizontal transport and downwelling balancing the upwelling initiated at the center. Overall, within the cyclone area of influence, the residual TC effect after 30 days is a slight cooling in the top $30 \mathrm{~m}$, warming in the subsurface layer, and cooling in deeper waters.

Temperature anomalies in the cyclones' wakes leave a residual signature in the model climatology, suggesting a persistent contribution of TCs on the ocean climate but of lower importance than previously claimed. The climatological effect of cyclones is mixing-induced warming of up to $0.12^{\circ} \mathrm{C}$ in the $20-300-\mathrm{m}$ layer south of $20^{\circ} \mathrm{S}$ and a cooling of up to $0.08^{\circ} \mathrm{C}$ in the $50-500 \mathrm{~m}$ associated with vertical advection north of $20^{\circ} \mathrm{S}$. These anomalies are weak but significant compared to the model error associated with the forcing uncertainty and TC-extraction method (section 3) and to sampling error (the rate of change in the heat budget is less than $10 \%$ of the forcing term).

Our finding that vertical advection has a lasting effect in the southwest Pacific region is consistent with the 
recent results of Scoccimaro et al. (2011) but contrasts with those of Price (1981). The latter describes upwelling and downwelling as compensating processes with no lasting effect. This is only exactly true for a closed system with no lateral exchange. In our simulations, there is substantial but not exact compensation by downwelling in the cyclone's footprint because of nonzero lateral transports. Therefore, the only relevant requirement is that the volume integral of heat advection equals the surface integral of heat fluxes at the system's boundaries (divergence theorem). Integrated over the whole region, we find that advection causes a net heat loss through the open boundaries, compensating for surface input. It produces a deep cooling in the center and weaker warming on the periphery of the cyclone distribution. In a statistical sense, the ocean responds to the cyclones' probability density function (PDF) with upwelling affecting high PDF zones and downwelling the periphery.

Sriver and Huber (2010) also show negative anomalies at 500-1500-m depths and suggest that they may be associated with vertical mixing. In our case, TC-induced vertical mixing has no impact at such depth, even though strong near-inertial oscillations are seen to propagate to great depths. Because of the effect of advection, the heat content anomaly below the mixed layer is only about a fifth of that expected if vertical mixing were the only player. Consequently, previous studies based on the latter assumption (e.g., Emanuel 2001; Sriver and Huber 2007; Pasquero and Emanuel 2008) would produce an excessive amount of heat input from the atmosphere ${ }^{6}$ and misconceive the process of heat storage and spreading across the ocean. More importantly, the seasonal cycle has a major impact on the amount of ocean heat storage as winter entrainment restores back to the surface $60 \%$ of the subsurface heat content anomaly. This is in agreement with suggestions by Jansen et al. (2010) from observations. Over the year, the surface flux anomaly is only $3.10^{-3} \mathrm{PW}$ and a weak positive temperature anomaly $\left(0.07^{\circ} \mathrm{C}\right.$ in regional average) remains in the permanent thermocline. The deep cold anomaly (with a mean value of $-0.02^{\circ} \mathrm{C}$ ) also presents some seasonal modulation by surface forcing but is more affected by the interannual variability of oceanic circulation.

One limitation of our study is the too-large amount of TCs that are weaker than observed. This would impact the intensity of SST and possibly the 3D oceanic response,

\footnotetext{
${ }^{6}$ Sriver and Huber (2007) estimate $0.26 \mathrm{PW}$ of global heat input due to TCs. We find $3 \%$ of this number in the southwest Pacific (if winter reemergence is not considered), for about $10 \%$ of world TCs found in this region. That number thus amounts to a third of the estimation by Sriver and Huber (2007). Further, accounting for winter reemergence, we only get about $10 \%$ of their $0.26 \mathrm{PW}$.
}

but we believe that the overall impact of cyclones would remain weak at the climatological scale. On the other hand, our method to remove extreme TC winds gives an uncertainty associated with the remaining filtered vortices. We estimated that these vortices have a residual thermal effect of less than $10 \%$, indicating a possible underestimation of the ocean response. However, this residual effect is probably similar to that of tropical depressions, which are numerous in the region. Also, in our study, we focused on the cyclone momentum forcing; neither the thermal anomalous structure of the cyclone nor the complex air-sea coupling that would affect both their intensity and oceanic impact is accounted for. Considering these may affect the details of surface cooling in the cyclone wake, especially the restoring process, but the subsurface processes would be less affected. Nevertheless, it will be useful to readdress our questions in the context of high-resolution coupled oceanatmosphere modeling.

Acknowledgments. We appreciate financial support from the IRD. In particular, the PC cluster used for ROMS and WRF simulations was financed through IRD's scientific computing effort project SPIRALES. We also thank three anonymous reviewers who helped us to substantially improve our manuscript.

\section{APPENDIX}

\section{KPP}

The KPP scheme (Large et al. 1994) parameterizes the oceanic vertical turbulent fluxes of scalars and momentum in terms of $K$ closure of turbulent fluxes $\overline{w^{\prime} T^{\prime}}=-K_{T}\left(\partial T / \partial z-\gamma_{T}\right)$, where primes indicate turbulent quantities; $w$ is the vertical velocity; $T$ is temperature here but could be any scalar quantity or horizontal velocity component; and $K_{T}$ is the vertical eddy diffusivity. The nonlocal transport term $\gamma_{T}$ is nonzero only in the convective surface layer but is neglected here on the basis that turbulent fluxes induced by TCs are dominated by wind stirring and shear instabilities. The boundary layer $K$ profile is computed as the product of the boundary layer thickness $h_{\mathrm{bl}}$, a depth-dependent turbulent velocity scale $w_{s}$, and a nondimensional shape function $G$. Here, $h_{\mathrm{bl}}$ is largely dependent on surface buoyancy and momentum forcing and is determined by equating a bulk Richardson number to a critical value. The shape function $G$ is determined by matching the mixing coefficients and their first vertical derivatives to surface layer values (at the near-surface boundary) and to interior values (at the boundary layer depth). In the surface layer, $K_{T}$ is formulated to agree with the similarity theory of 
turbulence. In the stratified interior, it is determined by the superposition of three processes: vertical shear instability, internal wave breaking, and convective adjustment (double diffusion is neglected here). The continuity imposed between boundary layer and interior mixing is an essential component of this formulation because it provides appropriate conditions for shear mixing by strong currents at the base of the boundary layer. This property is particularly important in the study of storm forcing where both wind stirring and shear mixing are active players. Details of the KPP formulation are given below.

\section{a. Interior mixing}

The mixing coefficient in the stratified interior is

$$
K_{T}=\underbrace{10^{-3}}_{\mathrm{A}}+\underbrace{5 \times 10^{-3}\left[1-\left(\frac{\underbrace{0.7}_{0 \leq \cdots \leq 1}}{\mathrm{Ri}}\right)^{2}\right]^{3}}_{\mathrm{B}}+\underbrace{0.1}_{\mathrm{C}},
$$

where $\mathrm{Ri}$ is the local Richardson number,

$$
\mathrm{Ri}=\frac{-\frac{g}{\rho_{0}} \frac{\partial \rho}{\partial z}}{\left(\frac{\partial u}{\partial z}\right)^{2}+\left(\frac{\partial v}{\partial z}\right)^{2}},
$$

with usual notations for density of seawater and horizontal component of current velocities. The terms A, B, and $\mathrm{C}$ represent the three mixing processes: internal wave breaking, vertical shear instability, and convective adjustment.

\section{b. Boundary layer mixing}

\section{1) BOUNDARY LAYER THICKNESS $h_{\mathrm{bl}}$}

Here, $h_{\mathrm{bl}}$ is given by the minimum depth where the bulk Richardson number reaches its critical value $\left(\mathrm{Ri}_{c}=0.3\right)$,

$$
\begin{aligned}
& \operatorname{Ri}_{\text {bulk }}\left(h_{\mathrm{bl}}\right) \\
& =\frac{-g\left[\rho_{\text {surf }}-\rho\left(h_{\mathrm{bl}}\right)\right] h_{\mathrm{bl}}}{\rho_{0}\left\{\left[u_{\text {surf }}-u\left(h_{\mathrm{bl}}\right)\right]^{2}+\left[v_{\text {surf }}-v\left(h_{\mathrm{bl}}\right)\right]^{2}+V_{t}^{2}\left(h_{\mathrm{bl}}\right)\right\}} \\
& \quad=\mathrm{Ri}_{c}=0.3,
\end{aligned}
$$

where $V_{t}$ is the velocity scale of the turbulent shear,

$$
V_{t}^{2}\left(h_{\mathrm{bl}}\right)=\frac{C_{v} \sqrt{-\beta_{T}}}{\operatorname{Ri}_{c} \kappa^{2}} \sqrt{c_{s} \varepsilon} h_{\mathrm{bl}} N w_{s} .
$$

The term $C_{v}=1.8$ is the ratio of interior Brunt-Väisälä frequency to the Brunt-Väisälä frequency at the entrainment depth; $\beta_{T}=-0.2$ is the ratio of entrainment buoyancy flux to surface buoyancy flux; $\kappa=0.4$ is von Kármán's constant; $c_{s}=98.96$ is a constant used in the calculation of the dimensionless flux profiles; $\varepsilon=0.1$ is the nondimensional extent of the surface layer; $N$ is the Brunt-Väisälä frequency; and $w_{s}$ is the turbulent velocity scale for scalars.

In case of stable buoyancy forcing $\left(B_{f}>0\right), h_{\mathrm{bl}}$ is taken as the minimum of the $h_{\mathrm{bl}}$ value computed above and the Ekman depth $h_{e}=0.7 u^{*} / f$, where $u^{*}=\left|\tau_{0}\right| / \rho_{0}$ is the friction velocity.

Buoyancy forcing is computed as $B_{f}=g\left[\alpha Q_{\text {total }}-\right.$ $\left.\beta(E-P) S-\left(\alpha I h_{\mathrm{bl}} / \rho C_{p}\right)\right]$, where $\alpha$ is the thermal expansion coefficient and $\beta$ is the saline contraction coefficient.

\section{2) Turbulent VELOCity SCAlE}

Here,

$$
w_{s}=\left\{\begin{array}{lll}
\kappa \sqrt[3]{-28.86 u^{*}+98.96 \kappa \sigma w^{* 3}} & \text { for } \sigma<\varepsilon \\
\kappa \sqrt[3]{-28.86 u^{*}+98.96 \kappa \varepsilon w^{*} 3} & \text { for } \sigma \geq \varepsilon
\end{array},\right.
$$

where $\sigma$ is the nondimensional vertical coordinate in the boundary layer ( 0 at the surface and 1 at the base).

\section{3) $K$ PROFILE}

For $K_{T}=h_{\mathrm{bl}} w_{s}(\sigma) G(\sigma), G(\sigma)$ is a cubic polynomial, such that

- $G(0)=0, K=0$ at the surface;

- $(\partial G(0) / \partial \sigma)=1$, linear reduction of flux with distance in the surface layer;

- $G(1)=\left(K_{T}\left(h_{\mathrm{bl}}\right) / h_{\mathrm{b} 1} w_{s}(1)\right)$, match of boundary layer and interior diffusivities at $h_{\mathrm{bl}}$; and

- $(\partial G(1) / \partial \sigma)=(\partial / \partial \sigma)\left[K\left(h_{\mathrm{bl}}\right) / h_{\mathrm{bl}} w(1)\right]$, match of boundary layer and interior derivatives at $h_{\mathrm{bl}}$.

\section{REFERENCES}

Bao, J. W., J. M. Wilczak, J. K. Choi, and L. H. Kantha, 2000: Numerical simulations of air-sea interaction under high wind conditions using a coupled model: A study of hurricane development. Mon. Wea. Rev., 128, 2190-2210.

Bender, M. A., I. Ginis, and Y. Kurihara, 1993: Numerical simulations of tropical cyclone-ocean interaction with a high-resolution coupled model. J. Geophys. Res., 98, 23 245-23 263.

Boccaletti, G., R. Ferrari, and B. Fox-Kemper, 2007: Mixed layer instabilities and restratification. J. Phys. Oceanogr., 37, 2228-2250. 
Chang, S. W., and R. A. Anthes, 1978: Numerical simulations of oceans non-linear, baroclinic response to translating hurricanes. J. Phys. Oceanogr., 8, 468-480.

Couvelard, X., P. Marchesiello, L. Gourdeau, and J. Lefevre, 2008: Barotropic zonal jets induced by islands in the southwest $\mathrm{Pa}$ cific. J. Phys. Oceanogr., 38, 2185-2204.

D'Asaro, E. A., 2003: The ocean boundary layer below Hurricane Dennis. J. Phys. Oceanogr., 33, 561-579.

_ - T. B. Sanford, P. P. Niiler, and E. J. Terrill, 2007: Cold wake of Hurricane Frances. Geophys. Res. Lett., 34, L15609, doi: 10.1029/2007GL030160.

De Boyer Montégut, C. D., G. Madec, A. S. Fischer, A. Lazar, and D. Iudicone, 2004: Mixed layer depth over the global ocean: An examination of profile data and a profile-based climatology. J. Geophys. Res., 109, C12003, doi:10.1029/2004JC002378.

Emanuel, K., 2001: Contribution of tropical cyclones to meridional heat transport by the oceans. J. Geophys. Res., 106, $14771-$ 14781.

Greatbatch, R. J., 1983: On the response of the ocean to a moving storm-The non-linear dynamics. J. Phys. Oceanogr., 13, 357-367.

Halliwell, G. R., Jr., L. K. Shay, J. K. Brewster, and W. J. Teague, 2011: Evaluation and sensitivity analysis of an ocean model response to Hurricane Ivan. Mon. Wea. Rev., 139, 921-945.

Huang, P. S., T. B. Sanford, and J. Imberger, 2009: Heat and turbulent kinetic energy budgets for surface layer cooling induced by the passage of Hurricane Frances (2004). J. Geophys. Res., 114, C12023, doi:10.1029/2009JC005603.

Jacob, S. D., and L. K. Shay, 2003: The role of oceanic mesoscale features on the tropical cyclone-induced mixed layer response: A case study. J. Phys. Oceanogr., 33, 649-676.

,-- A. J. Mariano, and P. G. Black, 2000: The 3D oceanic mixed layer response to Hurricane Gilbert. J. Phys. Oceanogr., 30, 1407-1429.

Jaimes, B., and L. K. Shay, 2009: Mixed layer cooling in mesoscale oceanic eddies during Hurricanes Katrina and Rita. Mon Wea. Rev., 137, 4188-4207.

$\longrightarrow$, and _ 2010: Near-inertial wave wake of Hurricanes Katrina and Rita over mesoscale oceanic eddies. J. Phys. Oceanogr., 40, 1320-1337.

Jansen, M. F., R. Ferrari, and T. A. Mooring, 2010: Seasonal versus permanent thermocline warming by tropical cyclones. Geophys. Res. Lett., 37, L03602, doi:10.1029/2009GL041808.

Jourdain, N. C., P. Marchesiello, C. E. Menkes, J. Lefevre, E. M. Vincent, M. Lengaigne, and F. Chauvin, 2011: Mesoscale simulation of tropical cyclones in the South Pacific: Climatology and interannual variability. J. Climate, 24, 3-25.

Kanamitsu, M., W. Ebisuzaki, J. Woollen, S.-K. Yang, J. J. Hnilo, M. Fiorino, and G. L. Potter, 2002: NCEP-DOE AMIP-II reanalysis (R-2). Bull. Amer. Meteor. Soc., 83, 1631-1643.

Kunze, E., 1985: Near-inertial wave propagation in geostrophic shear. J. Phys. Oceanogr., 15, 544-565.

Large, W. G., J. C. McWilliams, and S. C. Doney, 1994: Oceanic vertical mixing: A review and a model with a nonlocal boundary layer parameterization. Rev. Geophys., 32, 363-403.

Leipper, D. F., 1967: Observed ocean conditions and Hurricane Hilda. J. Atmos. Sci., 24, 182-196.

Lloyd, I. D., and G. A. Vecchi, 2011: Observational evidence for oceanic controls on hurricane intensity. J. Climate, 24,1138-1153.

Marchesiello, P., J. C. McWilliams, and A. Shchepetkin, 2001: Open boundary conditions for long-term integration of regional oceanic models. Ocean Modell., 3, 1-20.

_ - J. Lefevre, A. Vega, X. Couvelard, and C. Menkes, 2010: Coastal upwelling, circulation and heat balance around
New Caledonia's barrier reef. Mar. Pollut. Bull., 61, 432448.

- X. Capet, C. Menkes, and S. C. Kennan, 2011: Submesoscale dynamics in tropical instability waves. Ocean Modell., 39, 31-46.

McPhaden M. J., and Coauthors, 2008: Ocean-atmosphere interactions during Cyclone Nargis. Eos, Trans. Amer. Geophys. Union, 90, 53, doi:10.1029/2009EO070001.

McWilliams, J. C., 2006: Fundamentals of Geophysical Fluid Dynamics. Cambridge University Press, 249 pp.

Menkes, C. E. R., J. G. Vialard, S. C. Kennan, J. P. Boulanger, and G. V. Madec, 2006: A modeling study of the impact of tropical instability waves on the heat budget of the eastern equatorial Pacific. J. Phys. Oceanogr., 36, 847-865.

Pasquero, C., and K. Emanuel, 2008: Tropical cyclones and transient upper-ocean warming. J. Climate, 21, 149-162.

Penven, P., L. Debreu, P. Marchesiello, and J. C. McWilliams, 2006: Evaluation and application of the ROMS 1-way embedding procedure to the central California upwelling system. Ocean Modell., 12, 157-187.

Powell, M. D., P. J. Vickery, and T. A. Reinhold, 2003: Reduced drag coefficient for high wind speeds in tropical cyclones. Nature, 422, 279-283.

Price, J. F., 1981: Upper ocean response to a hurricane. J. Phys. Oceanogr., 11, 153-175.

— , T. B. Sanford, and G. Z. Forristall, 1994: Forced stage response to a moving hurricane. J. Phys. Oceanogr., 24, 233-260.

, J. Morzel, and P. P. Niiler, 2008: Warming of SST in the cool wake of a moving hurricane. J. Geophys. Res., 113, C07010, doi:10.1029/2007JC004393.

Pudov, V. D., A. A. Varfolomeev, and K. N. Fedorov, 1979: Vertical structure of the wake of a typhoon in the upper ocean. Okeanologiya, 21, 142-146.

Samson, G., H. Giordani, G. Caniaux, and F. Roux, 2009: Numerical investigation of an oceanic resonant regime induced by hurricane winds. Ocean Dyn., 59, 565-586.

Sanford, T. B., J. F. Price, J. B. Girton, and D. C. Webb, 2007: Highly resolved observations and simulations of the ocean response to a hurricane. Geophys. Res. Lett., 34, L13604, doi:10.1029/2007GL029679.

Schade, L. R., and K. A. Emanuel, 1999: The ocean's effect on the intensity of tropical cyclones: Results from a simple coupled atmosphere-ocean model. J. Atmos. Sci., 56, 642-651.

Scoccimarro, E., and Coauthors, 2011: Effects of tropical cyclones on ocean heat transport in a high-resolution coupled general circulation model. J. Climate, 24, 4368-4384.

Shay, L. K., and E. W. Uhlhorn, 2008: Loop current response to Hurricanes Isidore and Lili. Mon. Wea. Rev., 136, 3248-3274.

_ R. L. Elsberry, and P. G. Black, 1989: Vertical structure of the ocean current response to a hurricane. J. Phys. Oceanogr., 19, 649-669.

_ P. G. Black, A. J. Mariano, J. D. Hawkins, and R. L. Elsberry, 1992: Upper ocean response to Hurricane Gilbert. J. Geophys. Res., 97, 20 227-20 248.

, G. J. Goni, and P. G. Black, 2000: Effects of a warm oceanic feature on Hurricane Opal. Mon. Wea. Rev., 128, 1366-1383.

Shchepetkin, A. F., and J. C. McWilliams, 2005: The Regional Oceanic Modeling System (ROMS): A split-explicit, free-surface, topography-following-coordinate oceanic model. Ocean Modell., 9, 347-404.

Sriver, R. L., and M. Huber, 2007: Observational evidence for an ocean heat pump induced by tropical cyclones. Nature, 447, 577-580. 
_ and - 2010: Modeled sensitivity of upper thermocline properties to tropical cyclone winds and possible feedbacks on the Hadley circulation. Geophys. Res. Lett., 37, L08704, doi:10.1029/2010GL042836.

,$- \ldots$, and J. Nusbaumer, 2008: Investigating tropical cycloneclimate feedbacks using the TRMM Microwave Imager and the Quick Scatterometer. Geochem. Geophys. Geosyst., 9, Q09V11, doi:10.1029/2007GC001842.

Vincent, E. M., M. Lengaigne, C. E. Menkes, N. C. Jourdain, P. Marchesiello, and G. Madec, 2011: Interannual variability of the South Pacific convergence zone and implications for tropical cyclone genesis. Climate Dyn., 36, 1881-1896.

, G. Madec, J. Vialard, G. Samson, N. Jourdain, C. E. Menkes, and S. Jullien, 2012: Processes setting the characteristics of sea surface cooling induced by tropical cyclones. J. Geophys. Res., 117, C02020, doi:10.1029/2011JC007396.

Withee, G. W., and A. Johnson, 1976: Buoy observations during Hurricane Eloise (September 19 to October 11, 1975). U.S. Department of Commerce NOAA/NSTL Station Data Rep., 21 pp. 